\title{
SARS-CoV-2 expresses a microRNA-like small RNA able to selectively repress host genes
}

Authors: Paulina Pawlica ${ }^{1,2, *}$, Therese A. Yario ${ }^{1}$, Sylvia White ${ }^{3}$, Jianhui Wang ${ }^{3}$, Walter N. Moss ${ }^{4}$, Pei Hui ${ }^{3}$, Joseph M. Vinetz ${ }^{5}$, Joan A. Steitz ${ }^{*}$

\section{Affiliations}

${ }^{1}$ Department of Molecular Biophysics and Biochemistry, Howard Hughes Medical Institute, Yale University School of Medicine, New Haven, CT 06536, USA

${ }^{2}$ Current address: Department of Microbiology, Icahn School of Medicine at Mount Sinai, New York, NY 10029, USA

${ }^{3}$ Department of Pathology, Yale University School of Medicine, New Haven, CT 06536, USA

${ }^{4}$ Roy J. Carver Department of Biochemistry, Biophysics, and Molecular Biology, lowa State University, Ames, IA 50011, USA

${ }^{5}$ Section of Infectious Diseases, Department of Internal Medicine, Yale School of Medicine, New Haven, CT 06520-8022, USA

*Correspondence to: joan.steitz@yale.edu and paulina.pawlica@mssm.edu 


\section{Abstract}

2 Severe acute respiratory syndrome coronavirus 2 (SARS-CoV-2), the causative agent of

3 coronavirus disease (COVID-19), continues to be a pressing health concern. In this study, we

4 investigated the impact of SARS-CoV-2 infection on host microRNA (miRNA) populations in

5 three human lung-derived cell lines, as well as in nasopharyngeal swabs from SARS-CoV-2

6 infected individuals. We did not detect any major and consistent differences in host miRNA

7 levels after SARS-CoV-2 infection. However, we unexpectedly discovered a viral miRNA-like

8 small RNA, named vmiR-5p (for viral miRNA), derived from the SARS-CoV-2 ORF7a transcript.

9 Its abundance ranges from low to moderate as compared to host miRNAs. vmiR-5p functionally

10 associates with Argonaute proteins - core components of the RNA interference pathway -

11 leading to downregulation of host transcripts. One such host messenger RNA encodes Basic

12 Leucine Zipper ATF-Like Transcription Factor 2 (BATF2), which is linked to interferon signaling.

13 We demonstrate that vmiR-5p production relies on cellular machinery, yet is independent of

14 Drosha protein, and is enhanced by the presence of a strong and evolutionarily conserved

15 hairpin formed within the ORF7a sequence. 


\section{Significance statement}

2 We discovered that severe acute respiratory syndrome coronavirus 2 (SARS-CoV-2) expresses

3 a small viral non-coding RNA, named vmiR-5p (for viral miRNA), derived from the ORF7a

4 transcript. vmiR-5p associates with the cellular RNA interference machinery to regulate host

5 transcripts likely via target silencing. The production of vmiR-5p relies on cellular machinery and

6 the formation of a strong hairpin within ORF7a sequences. This newly-described vmiR-5p may

7 contribute to SARS-CoV-2 pathogenesis and could become a target for therapeutic intervention.

8 


\section{Introduction}

2 Coronaviruses are large single-stranded positive-sense RNA viruses that infect various animals;

3 in humans coronaviral infection results in mild to severe respiratory disease. $\beta$-coronaviruses,

4 such as severe acute respiratory syndrome coronavirus (SARS-CoV) and Middle East

5 respiratory syndrome coronavirus (MERS-CoV), cause very severe disease in humans, while

6 the recently emerged severe acute respiratory syndrome coronavirus 2 (SARS-CoV-2) results in coronavirus disease (COVID-19) characterized by wide array of symptoms from mild to serious

8 illness. SARS-CoV-2 is the cause of the COVID-19 pandemic due to its high transmissibility and emergence of novel variants (1). It is crucial to understand all aspects of SARS-CoV-2 pathogenesis in order to develop multiple tools to combat the constantly-adapting virus.

12 in post-transcriptional regulation of gene expression in animals and plants (2). During canonical

13 miRNA biogenesis, RNA polymerase II transcribes primary miRNAs (pri-miRNAs) characterized

14 by formation of strong hairpins that are recognized and cleaved by the endonuclease Drosha,

15 resulting in $\sim 70$ nt-long precursor miRNAs (pre-miRNAs). Pre-miRNAs are exported to the

16 cytoplasm, where they are subjected to yet another cleavage by Dicer, giving rise to 22 nt-long

17 miRNA duplexes, which are then loaded onto Argonaute (Ago) proteins. The passenger strand

18 is removed, and the mature miRNA guides Ago proteins to partially complementary target

19 sequences, usually located in the 3' untranslated region (UTR) of messenger RNAs (mRNAs).

20 miRNA binding leads to translation inhibition and/or mRNA decay by decapping and

21 deadenylation. In the special case where the miRNA is nearly perfectly complementary to its

22 target mRNA, it directs Ago2 (one of four Ago proteins in humans) to cleave the mRNA target; a

23 function typically associated with small interfering RNAs (siRNAs) (2). These modes of target

24 repression belong to RNA interference (RNAi) pathway, but Ago2-mediated cleavage is more

25 potent in target silencing and requires lower intracellular copy numbers than the canonical

26 miRNA action mode (3). Importantly, miRNA profiles differ between cell types and 
1 developmental stages, and a single miRNA can downregulate multiple transcripts, precisely

2 regulating gene expression dependent on the cell's needs. In humans, most mRNAs are

3 regulated by miRNAs, and aberrant miRNA levels are linked to disease (2).

$4 \quad$ Viruses often hijack the miRNA pathway; either by depleting host miRNAs or by

5 producing their own miRNAs (reviewed in $(4,5)$ ). Some examples of host miRNA regulation

6 include: selective host miRNA decay mediated by certain herpesviral transcripts in a process

7 called target-directed miRNA degradation (TDMD; reviewed in $(6,7)$ ), and widespread miRNA

8 polyadenylation by poxvirus poly $(A)$ polymerase, which results in miRNA decay (8). Viruses can

9 produce their own miRNAs, often via non-canonical biogenesis pathways; especially

10 cytoplasmic viruses have devised multiple strategies to bypass the requirement for nuclear

11 Drosha $(4,9)$. It has been proposed that coronaviruses, SARS-CoV and SARS-CoV-2, produce

12 small viral RNAs (svRNAs) involved in viral pathogenesis independently of RNAi pathway (10,

13 11). One recent study suggested the existence of miRNA-like RNAs produced by SARS-CoV-2,

14 which might contribute to inflammation and type I interferon (IFN) signaling (12).

15 In this study, by using a small RNA-seq library preparation protocol that selectively

16 enriches for miRNAs, we unexpectedly discovered a miRNA-like viral ncRNA, named vmiR-5p

17 (for viral miRNA), expressed by SARS-CoV-2. We show that it associates with Ago proteins and

18 has the potential to regulate host transcripts likely via target silencing. We demonstrate that

19 vmiR-5p production relies on cellular machinery, but is independent of Drosha proteins and is

20 enhanced by the presence of a strong hairpin formed within ORF7a sequences. This newly-

21 described vmiR-5p may contribute to SARS-CoV-2 pathogenesis and could become a target for

22 therapeutic intervention. 


\section{Results}

\section{SARS-CoV-2 infection has minimal impact on the miRNA population of its host cell}

3 To explore how SARS-CoV-2 affects host miRNA populations, we infected three lung-derived

4 human cell lines either at high multiplicity of infection (MOI of 5) to detect the possible direct

5 impact of the incoming virions on host miRNAs, or at low $\mathrm{MOI}(0.05)$ to assess the effect of viral

6 replication on these small RNA species. We used non-small-cell lung cancer cells Calu-3, lung

7 adenocarcinoma cells A549 transduced with the human viral receptor, angiotensin-converting

8 enzyme 2 (ACE2), and lung adenocarcinoma cells PC-9, all of which we found to support

9 SARS-CoV-2 replication (red, yellow and blue dots, respectively, in Fig. 1A). SARS-CoV-2

10 replicated better in Calu-3 and PC-9 cell lines than in the A549-hACE2 cell line, possibly

11 because the viral receptor is greatly overexpressed in the last cell line (Fig. S1A), which could

12 sequester budding virions at the cell surface.

13 Small RNA sequencing was performed at both $6 \mathrm{~h}$ and $24 \mathrm{~h}$ post infection (hpi) at high

$14 \mathrm{MOI}$ and $48 \mathrm{hpi}$ at low $\mathrm{MOI}$, as well as for the uninfected controls (at the 24-h time point). The

15 vast majority $(84 \% \pm 5 \%)$ of obtained reads mapped to host miRNAs (green bars in Fig. $1 \mathrm{~B}$ ) with

16 an average read length of 22-23 nts (Fig. S1B). Overall, only a small fraction of small RNA

17 reads mapped to the viral genome $(0.07 \pm 0.01 \%, 0.21 \pm 0.04 \%$ and $1.63 \pm 0.67 \%$ at high MOls 24

18 hpi for Calu-3, PC-9 and A549-hACE2, respectively; blue bars in Fig. 1B). This number is in

19 agreement with similar studies of svRNAs in other RNA viruses (10-12).

SARS-CoV-2 infection resulted in minimal alteration of some host miRNA levels, but no

21 miRNA displayed a uniformly significant change across all three cell lines (red and blue dots in

22 Figs. $1 \mathrm{C}$ and $\mathrm{S} 1 \mathrm{C}$ ). To identify any consistent shifts in host miRNA levels across the three cell

23 lines, we generated a heat map of fold-changes for miRNAs that were significantly altered, by at

24 least two-fold, in at least one condition (Fig. S1D). Some of these trends were further examined

25 by Northern blotting of RNA from Calu-3 cells infected with SARS-CoV-2 at low MOI. The most

26 reproducibly changed (upregulated) miRNA, although not reaching statistical significance, was 
1 miR-210-3p (Fig. S1E). Interestingly, GO term analyses for validated miR-210-3p targets (13)

2 revealed that this miRNA is involved in regulating responses to cellular stimuli, such as hypoxia

3 (Fig. S1F). In addition, in two datasets obtained from lung biopsies of COVID-19 patients (14,

4 15) miR-210-3p targets were downregulated to a greater extent than other human mRNAs (Fig.

$5 \mathrm{~S} 1 \mathrm{G})$.

Of note, the miRNA changes observed by small RNA-seq were not detected by TaqMan

7 RT-qPCR from nasopharyngeal swabs from SARS-CoV-2-positive individuals (Fig. 1D).

8 Interestingly, analysis of unnormalized Ct values revealed that after SARS-CoV-2 infection the

9 overall miRNA abundance increased, while the levels of ncRNAs from two other small RNA

10 classes (small nuclear RNA U6B and small nucleolar RNA U44) decreased (Fig. S1H),

11 suggesting that miRNAs might escape the viral host shut-off effect (16). This agrees with the

12 reported stabilization of miRNAs in circulating exosomes $(17,18)$. Thus, it may be possible to

13 devise small RNA-mediated treatments to treat COVID-19. Overall, we did not find any major

14 impact of SARS-CoV-2 infection on host-cell miRNA populations.

SARS-CoV-2 expresses a miRNA-like small RNA derived from the ORF7a sequence

17 Of the reads derived from SARS-CoV-2, 5.2\% $\pm 2.8 \%$ mapped to a single peak within the

18 ORF7a sequence (Figs. 2A and S2A). ORF7a encodes a SARS-CoV-2 accessory protein, a

19 putative type-I transmembrane protein involved in antagonizing the type I IFN response

20 (reviewed in (19)). The reads mapping to the ORF7a sequence are approximately 20 nt-long

21 (Fig. 2B). Because the small RNA libraries were dominated by host miRNAs and a $U$ (the

22 preferred 5'-terminal nucleotide for Ago loading (20)) is present at the $5^{\prime}$ end, we interrogated

23 whether this RNA could represent a viral miRNA-like ncRNA.

24 Since miRNA biogenesis relies on formation of RNA hairpins, we asked whether such an

25 RNA structure could be found within the viral ORF7a sequence. Indeed, the putative ncRNA

26 together with its downstream region forms a strong hairpin ( $\Delta \mathrm{G}=-19.7 \mathrm{kcal} / \mathrm{mol}$; Fig. $2 \mathrm{C})$; this 
1 stability value is found to be unusually low given the AU-rich nucleotide composition, suggesting

2 that it arose through an evolutionarily-driven process; indeed, the thermodynamic Z-score

3 was -5.5 (meaning that the WT sequence is more than 5 standard deviations more stable than

4 random). In addition, a comprehensive analysis of RNA structural motifs in SARS-CoV-2 found

5 that this hairpin is one of the few (nine) that show evidence of statistically significant sequence

6 covariation - a feature of evolutionary conservation (21). The formation of the hairpin is also in

7 agreement with previously-reported structure probing reactivity datasets (22-25), where the only

8 reactive nucleotides occur in loop regions. Since the newly-identified ncRNA is derived from this

9 hairpin - which is a hallmark of miRNA biogenesis (26) - we named it viral miRNA-5p (vmiR-

$105 p)$. There exists sequence and structure similarity of the RNA hairpin between SARS-CoV-2,

11 bat coronavirus RaTG13, and a pangolin coronavirus (Fig. S2B).

12 vmiR-5p and its pre-miRNA-sized precursor are detectable by Northern blotting of RNA

13 from Calu-3 cells infected with SARS-CoV-2 at low MOI (Fig. 2D). Interestingly, the most

14 prevalent species of vmiR-5p observed by Northern blotting are $25-27$ nt-long, longer than those

15 identified by small RNA sequencing. Since the small RNA library was size-selected, this could

16 mean that vmiR-5p is in fact more abundant than when quantified by RNA-seq. However,

17 because miRNAs are usually $\sim 22$ nt-long, vmiR-5p or its precursor could have an additional

18 RNAi-independent function. vmiR-5p was detected in individuals infected with SARS-CoV-2

19 (Fig. 2E) and its abundance correlated positively with viral load/genomic RNA (as measured by

20 the levels of RNA-dependent RNA polymerase; RdRp).

\section{2 vmiR-5p binds Ago to repress human mRNAs}

23 Since the miRNA program is executed by Argonaute proteins, we asked whether vmiR-5p

24 associates with these host proteins. We performed anti-pan-Ago RNA immunoprecipitation

25 (RIP) on extracts from Calu-3 and A549-hACE2 cells infected with SARS-CoV-2 at high MOI,

26 followed by small RNA sequencing. In both cell lines, vmiR-5p associates with Ago proteins, 
1 although slightly more weakly than most host-cell miRNAs; its expression levels are comparable

2 to low or moderately expressed host miRNAs (Fig. 3A). To obtain enough material for Northern

3 blotting experiments, we performed an anti-HA RIP from Calu-3 cells transduced with either

4 empty vector or FLAG-HA-tagged human Ago2 (27). Although weak, Ago2 selectively bound

$5 \quad$ vmiR-5p, but not vmiR-3p. In these experiments, we observed slight RNA degradation likely

6 arising during the SARS-CoV-2 inactivation step (30 min incubation at RT). Perhaps this is the

7 reason why vmiR-5p bands in Fig. 3B migrate somewhat faster than those in Fig. 2D.

8 The role of Ago-associated small RNAs is to repress targeted mRNAs via sequence

9 complementarity, we thus computationally searched the repository of human mRNA transcripts

10 (obtained from GENECODE) for putative vmiR-5p targets. Considering the moderate expression

11 levels of vmiR-5p as compared to those of host miRNAs, we hypothesized that vmiR-5p might

12 rely on Ago2's ability to cleave its mRNA target. Since Ago2-mediated target cleavage tolerates

13 a limited number of mismatches $(28,29)$, we searched for mRNAs with high complementarity to

14 vmiR-5p (Table 1; Fig. 3C), and selected some of these for further validation.

15 Due to the widespread host-shutoff effect after infection with SARS-CoV-2 (16), we

16 were unable to perform meaningful quantification of mRNAs from infected cells. We thus

17 transfected synthetic vmiR-5p (annealed to a passenger strand) into HEK293T cells and

18 assayed transcript levels of predicted target mRNAs (Fig. 3D). Two mRNAs, Basic Leucine

19 Zipper ATF-Like Transcription Factor 2 (BATF2) and (Heparan Sulfate Proteoglycan 2) HSPG2,

20 were significantly downregulated (Fig. 3D). BATF2 has been linked to INF-gamma signaling via

21 association with Irf1 (30). HSPG2 is the core protein of a large multidomain proteoglycan that

22 binds and cross-links many extracellular matrix components; it interestingly participates in the

23 attachment of some viruses, including the coronavirus NL63 (31). We hypothesize that vmiR-5p

24 has the potential to repress human mRNAs that support the host IFN response, and perhaps to

25 inhibit viral superinfection. 


\section{Production of functional vmiR-5p depends on cellular machinery}

2 To assess whether vmiR-5p biogenesis can occur in a virus-free system, we transfected in vitro

3 transcribed RNA into HEK293T cells. A 100 nt-long viral RNA sequence (WT), alongside

4 counterparts containing mutations either in the $3^{\prime}$ portion $(\mathrm{m} 3 \mathrm{p})$ or in the $5^{\prime}$ portion $(\mathrm{m} 5 \mathrm{p})$ of the

5 hairpin (Fig. 4A) were transfected into cells and RNA samples collected after 6 h were analyzed

6 by Northern blotting (Fig. 4B). The WT sequence was processed inside cells to produce a 21

7 nt-long band of vmiR-5p, while the m3p did not yield efficient production of an RNA of such size.

8 To investigate whether the produced RNA functionally associates with Ago proteins, we

9 transfected in vitro transcribed RNA together with luciferase reporters containing 3' UTR

10 sequences complementary to either vmiR-5p or scrambled controls. The luciferase activity of

11 the reporter containing viral sequences was significantly decreased in the presence of the WT

12 ORF7a RNA (Fig. 4C), but not by the other constructs. Finally, we used Drosha knockout cell

13 lines (32) to show that the production of vmiR-5p occurs independently of this enzyme's activity

14 (Fig. 4D). These results clearly demonstrate that vmiR-5p is processed from a hairpin

15 independently of viral proteins and of cellular Drosha, and that it can be functionally loaded on

16 Ago.

\section{Discussion}

19 Here, we began by investigating the impact of SARS-CoV-2 infection on host miRNA

20 populations using three human lung-derived cell lines (at various MOls) and found no consistent

21 changes detected in all three cell lines (Figs. 1C and S1C). We also assessed the levels of

22 selected miRNAs in patient samples and again did not detect major differences after SARS-

23 CoV-2 infection (Fig. 1D). Other groups have also ventured into examining miRNA profiles

24 during SARS-CoV-2 infection, but there is little overlap between these prior studies (33-35) and

25 our results. Differences between the outcomes likely stem from the use of different methods of

26 RNA-seq library preparation $(36,37)$. Our libraries were prepared with the NEXTflex v2 kit, 
1 which has been shown to be highly selective for miRNAs (36), and contained $~ 84 \%$ host

2 miRNAs (Fig. 1B), while libraries that rely on template switching used by others (33) yield only

$3 \sim 17 \%$ miRNAs (37). The presence of additional reads in the latter libraries could result in

4 nonspecific alignment to miRNA loci. For example, miR-155-3p, which is believed to represent a

5 host miRNA passenger stand, was reported to increase upon SARS-CoV and SARS-CoV-2

6 infection (33), but we were unable to detect this miRNA either by sequencing or by Northern

7 blotting (data not shown). Similarly, miR-4485 was described to be upregulated in another study

8 (34), but it did not pass the abundance threshold (> 1 CPM) in our small RNA-seq analysis.

9 Also, other studies assessing the impact of various coronaviruses on host miRNA levels do not

10 support the notion that coronaviruses have major impact on host miRNA populations (38-41).

11 We cannot rigorously exclude the possibility that some host miRNAs levels are altered during

12 SARS-CoV-2 infection, but if so, these changes are likely minor.

Interestingly, in samples from individuals infected with SARS-CoV-2 all assessed host

14 miRNAs seemed to be stabilized, while — similar to what is known about host mRNAs in

15 infected cells (16) - U6B snRNA and U44 snoRNA levels decreased (Fig. S1H). These results

16 suggest that miRNAs might be resistant to the viral host-shutoff effect. Indeed, miRNAs can be

17 very stable because of their association with Ago proteins, especially when secreted in

18 exosomes $(2,17,18)$. It is tempting to speculate that, because of their high stability, small RNAs

19 could be successfully used as therapeutic agents against SARS-CoV-2. Regardless, we caution

20 against examining miRNA profiles using RT-qPCR and normalizing to ncRNAs from different

21 classes, such as snRNAs and snoRNAs.

In this study, we discovered that SARS-CoV-2 expresses an miRNA-like small RNA,

23 which we call vmiR-5p (Fig. 2). There are multiple examples of svRNAs expressed by RNA

24 viruses, such as influenza (42), enterovirus 71 (43), Hepatitis C (44), hepatitis A (45), Polio (44),

25 Dengue $(44,46)$, Vesicular Stomatitis (44), West Nile $(44,47)$, coronaviruses (10-12) and 
retroviruses $(48,49)$. It has been suggested that some svRNAs function through the host-cell RNAi pathway $(12,44,45)$, but most proposed roles are independent of this machinery $(10,11$, $42,43,50)$. As compared to other studies of SARS-CoV-2, we did not detect svRNAs derived

4 from the $\mathrm{N}$ gene $(10,12)$, which suggests that the functions of those is not related to RNAi

5 pathway. Interestingly, vmiR-5p was also detected by Meng and colleagues, but was not

6 selected for further validation (12). vmiR-5p is derived from the beginning of the coding sequence of the ORF7a transcript (Fig. 2B), which is the most abundant subgenomic viral RNA detected during SARS-CoV-2

9 infection $(33,51)$. The sequence of vmiR-5p is preserved in all SARS-CoV-2 isolates and

10 variants of concern, and is related to those of two other coronaviruses (Fig. S2). Interestingly,

11 ORF7a deletions, which lead to decreased innate immune suppression, occur frequently in

12 SARS-CoV-2, but affect almost exclusively the C-terminus of the protein, while the N-terminus

13 - where the vmiR-5p sequence is located - is preserved (52). These data and the observed

14 conservation of the hairpin containing vmiR-5p (21) support the notion that this sequence is 15 functional.

16 The abundance of vmiR-5p ranges from low to moderate as compared to host miRNAs

17 (Fig. 3A), similar to other svRNAs $(10,45,53)$, and is consistent with the idea that its

18 functionality relies on high complementarity to target mRNA, likely inducing mRNA cleavage.

19 Indeed, we have shown that vmiR-5p associates with human Ago proteins and that it can

20 repress human targets (Fig. 3). Using bioinformatics, we identified two host transcripts that are

21 significantly downregulated in the presence of a synthetic vmiR-5p, BATF2 and HSPG2 (Fig. 3

22 and Table 1). In addition to these, there are likely more targets that may be identified by cross-

23 linking ligation and sequencing of hybrid (CLASH; (54)) methodology. To address the

24 functionality of vmiR-5p in the context of viral infection, we attempted to use luciferase reporters,

25 but due to the host-shutoff effect there was almost no luciferase signal in infected cells. We

26 avoided using antisense oligonucleotides to block vmiR-5p because they would undoubtedly 
1 also suppress production of the ORF7a protein and inhibit viral replication. Upcoming studies

2 will focus on the construction of mutant viruses in which the ORF7a coding sequence and

3 hairpin formation are preserved.

Another intriguing possibility is that SARS-CoV-2 uses vmiR-5p to regulate the level of

5 its own negative-sense subgenomic RNAs, or of antigenomic RNAs (55). It is also plausible that

6 the viral hairpin, in addition to being the source of a viral miRNA, could have an additional

7 function independent of the RNAi pathway. RNA viruses have been shown to express regulatory

8 svRNAs. For example, svRNA1 from enterovirus-71 binds to a viral internal ribosome entry site

9 (IRES) to regulate translation of viral proteins (43). Another example is svRNAs from influenza

10 that associate with viral $\mathrm{RdRp}$, possibly enabling the switch from transcription to replication (50).

11 Finally, we addressed vmiR-5p biogenesis and were able to demonstrate that its

12 processing occurs via cellular machinery and relies on the formation of an RNA hairpin, but is

13 independent of Drosha protein (Fig. 4). Yet, it is possible that viral genes enhance this

14 processing pathway. Many viruses bypass Drosha to produce their pre-miRNAs, e.g. by utilizing

15 RNase Z $(56,57)$, Integrator complex (58) or a viral protein (such as HIV-1 TAT) (59). In some

16 instances, viral miRNAs biogenesis even relies on Ago2 cleavage (4). We speculate that Dicer,

17 which is responsible for production of the majority of host and viral miRNAs $(2,45,59,60)$, is

18 involved in vmiR-5p biogenesis. Future efforts will aim to uncover which enzymes are

19 responsible for vmiR-5p production.

20 In summary, viruses develop multiple ways to suppress host gene expression,

21 and multiple overlapping mechanisms often evolve. SARS-CoV-2 regulates host mRNA

22 expression on many levels: stability (16), export $(16,60)$, translation $(61-63)$ and

23 splicing (61). It is not surprising that yet another strategy, which utilizes the RNAi

24 pathway, to selectively target host - and perhaps viral — transcripts has evolved. 


\section{Acknowledgements}

3 We thank the members of the Steitz lab for advice and support. We are grateful to Dr. Craig

4 Wilen for the help in setting up BSL3 work. We thank Dr. Charles Rice for Hu7.5 cells and

$5 \quad$ Huh7.5 Drosha knockout cells (32). We thank Dr. Benjamin Israelow for a plasmid expressing

6 hACE2. We acknowledge the hard work of Yale's Environmental Health and Safety program, in

7 particular Benjamin Fontes. This work was funded by the NIH supplement 3P01CA016038-

$845 \mathrm{~S} 1$ (to J.A.S.), by NIH grant R01GM133810 grant (to W.N.M)., and by the Yale School of

9 Medicine Department of Internal Medicine, the Prostate Cancer Foundation, the Harrington

10 Discovery Institute, and the COVID-19 Early Treatment Fund (to J.M.V.). P.P. was supported by

11 NIH fellowship K99/R00 (K99GM129412/ R00GM129412). J.A.S. is an investigator of the

12 Howard Hughes Medical Institute.

\section{Author Contributions}

15 P.P. and J.A.S. designed experiments and interpreted the results. P.P. performed experiments

16 and analyzed data. T.A.Y. provided technical assistance. S.W., J.W., P.H., J.M.V. provided RNA

17 from nasopharyngeal swabs, W.N.M. contributed to computational analyses, P.P. and J.A.S.

18 wrote the manuscript.

20 Declaration of interest

21 Authors declare no competing interests. 


\section{Materials and Methods}

2 Cells. Calu-3 (ATCC) cells were cultured in Eagle's minimal essential medium (EMEM, ATCC)

3 with 10\% fetal bovine serum (FBS) and Penicillin/Streptomycin (Pen/Strep; GIBCO). PC-9 cells

4 (kind gift from Dr. Craig Wilen) were cultured in RPMI medium (GIBCO) with 10\% FBS and

5 Pen/Strep. A549 (ATCC) cells were transduced as described previously (27) with hACE2

6 plasmid and cultured in F-12 medium (GIBCO) with 10\% FBS, Pen/Strep and $1 \mu \mathrm{g} / \mathrm{ml}$ of

7 puromycin (GIBCO). Vero-E6 (ATCC), Huh7.5 and Huh7.5 Drosha knockout (kind gift from Dr.

8 Charles Rice; (32)) cells were cultured in DMEM with 10\% FBS, and Pen/Strep. Calu-3 cells

9 were transduced either with FLAG-HA-Ago2 (27) or pLVX (for empty vector control) and

10 cultured in the presence of $1 \mu \mathrm{g} / \mathrm{ml}$ of puromycin.

12 Viral stocks. To generate SARS-CoV-2 stocks, Vero-E6 were inoculated with P2 of SARS-

13 CoV-2 isolate USA-WA1/2020 (kind gift from Dr. Craig Wilen) at 0.01 multiplicity of infection

14 (MOI) for $1 \mathrm{~h}$, after which the inoculum was replaced with DMEM with 5\% FBS. After 3 days the

15 supernatant was harvested and clarified by centrifugation, concentrated on Ultra-15 Centrifugal

16 Filters (Amicon), aliquoted and stored at $-80^{\circ} \mathrm{C}$. Virus titers were determined by plaque assay

17 using Vero-E6 cells. All infectious growth was performed in a Biosafety Level 3 laboratory and

18 was approved by the Yale University Biosafety Committee.

Plaque assays. Vero-E6 cells were seeded at $4 \times 10^{5}$ cells/well in 12 -well plates. The next day,

21 medium was removed, and cells were incubated for $1 \mathrm{~h}$ at $37^{\circ} \mathrm{C}$ with $100 \mu$ s serially diluted

22 sample; plates were rocked every $15 \mathrm{~min}$. Next, $1 \mathrm{ml}$ of the overlay media (DMEM, $2 \%$ FBS,

$230.6 \%$ Avicel) was added to each well. 3 days later, the plates were fixed with $10 \%$ formaldehyde

24 for $30 \mathrm{~min}$, stained with crystal violet solution ( $0.5 \%$ crystal violet in $20 \%$ methanol) for $30 \mathrm{~min}$,

25 and then rinsed with water to visualize plaques. 
1 Samples for small RNA sequencing. For small RNA sequencing, $5 \times 10^{5}$ of Calu-3, $5 \times 10^{5}$ of

2 PC-9 or $1 \times 10^{5}$ of A549-hACE2 cells were plated per well in 6-well plates. Cells were infected 3 with SARS-CoV-2 at MOI either of 5 or 0.05 for $1 \mathrm{~h}$ in $200 \mu$ of inoculum and incubated for $1 \mathrm{~h}$

4 at $37^{\circ} \mathrm{C}$. After that, the cells were rinsed with PBS to remove the unbound virus and fresh were

5 media added. Cells were incubated for either $6 \mathrm{~h}$ and $24 \mathrm{~h}$ (MOI 5), or $48 \mathrm{~h}$ (MOI 0.05). In

6 addition, mock-treated controls were collected after $24 \mathrm{~h}$. Cells were harvested by removing the

7 media and adding TRIzol at each time point; supernatants were kept to assess viral titer by

8 plague assay. RNA isolation and library preparation was performed under BSL2+ confinement;

9 RNA concentration was measured by Qubit Fluorimeter (ThermoFisher) inside a biosafety

10 cabinet. $1 \mu \mathrm{g}$ of total RNA was used for library preparation using NEXTflex v2 kit (PerkinElmer)

11 according to the manufacturer's instructions. Libraries were amplified for 16 cycles and the

12 cDNA libraries were sequenced on the HiSeq 2500 Illumina platform.

14 Small RNA data processing. The reads were trimmed of adaptors using Cutadapt (64) with the

15 following settings -u 4 -O 7 -a N\{4\}TGGAATTCTCGGGTGCCAAGG -q 10 -m 18 -M. The reads

16 were mapped with bowtie2 (65) (--very-sensitive-local) to an index containing human and

17 SARS-CoV-2 genomes. miRNAs were counted by using featureCounts (66) and annotations

18 obtained from miRbase (67). For Ago IP counts, vmiR-5p was added to the annotation file and

19 treated as a host miRNA. Differential expression was determined using edgeR (68). Track

20 visualization was performed using an IGV browser (69) of generated with BEDtools (70) bed

21 files.

22

23 Patient samples and quantitative RT-PCR. The human study reported here from which

24 nasopharyngeal swab samples were obtained was approved by the Yale Human Research

25 Protection Program, (Protocol 2000027971). 
The nasopharyngeal swab samples were extracted using MagMAX mirVana Total RNA Isolation Kit (Catalog \# A27828), with the script A27828_FLEX_Biofluids for miRNA extraction

3 from biofluid samples on the KingFisher FLEX-96 Magnetic Particle Processor. Briefly, each 100

$4 \quad \mu \mathrm{l}$ specimen of nasopharyngeal swab in transportation medium was processed and the miRNA-

5 enriched RNA was collected in $50 \mu$ of elution buffer. miRNA RT-qPCR was performed using

6 TaqMan MicroRNA Assay (Applied Biosystems); for miR-16, miR-210-3p, miR-31-3p, miR-193-

7 5p, miR-193-3p, U6B and U44 pre-designed assays were ordered (Cat \# 4427975) and for

8 vmiR-5p, a custom assay to detect the sequence UUCUUGGCACUGAUAACAC was ordered

9 (Cat \# 4398987). RT-qPCR was performed according to the manufacturer's guidelines; briefly,

10 cDNA was prepared separately for each miRNA using the TaqMan MicroRNA Reverse

11 Transcription Kit (Applied Biosystems) and qPCR was performed using the TaqMan Fast

12 Advanced Master Mix (Applied Biosystems). For detection of viral RdRp, cDNA was prepared

13 using random primers and SuperScript III (Invitrogen) and qPCR was performed according to

14 the protocol (71) using oligonucleotides and a probe ordered from IDT (sequences are given in

15 Table 2). All work was done in BSL2+ conditions.

17 Northern blot analysis. $5 \times 10^{6}$ of Calu-3 cells were infected with SARS-CoV-2 at MOI 0.05 in

18 T75 flasks for $1 \mathrm{~h}$, after which the inoculum was replaced by fresh media, and cells were

19 incubated for either $24 \mathrm{~h}$ or $48 \mathrm{~h}$ (mock-treated samples were collected after $48 \mathrm{~h}$ ). Samples

20 were inactivated for $30 \mathrm{~min}$ in $5 \mathrm{ml}$ of TRIzol and RNA was isolated in BSL2+ conditions. $10-15$

$21 \mu \mathrm{g}$ of total RNA was separated by $15 \%$ urea-PAGE, electrotransferred to Hybond-NX

22 membrane (Amersham) and crosslinked with 1-ethyl-3-(3-dimethylaminopropyl) carbodiimide

23 (EDC) (72). miRNAs were detected using ${ }^{32} \mathrm{P}$ 5'-radiolabeled DNA probes. Densitometry was

24 performed by using Quantity One. 
miR-210-3p target and re-analysis of public data. Counts from RNA-seq experiments of lung biopsies were obtained from $(14,15)$. The data were divided into miR-210-3p targets (data from miRTarBase (73); excluding "weak" targets) and other transcripts. The data were plotted as cumulative distribution functions and compared to each other using Wilcoxon test.

Immunoprecipitation. For anti-pan Ago IP, $5 \times 10^{5}$ of Calu-3 cells or $1 \times 10^{5}$ of A549-hACE2 cells were infected with SARS-CoV-2 at MOI 5 for $24 \mathrm{~h}$. Cells were detached with trypsin-EDTA, pelleted and resuspended in $500 \mu \mathrm{l}$ of NET-2 buffer (50 mM Tris [pH 7.5], $150 \mathrm{mM} \mathrm{NaCl}$, and $0.05 \%$ NP-40). After 30 min of cell lysis inside the BSC, the nuclei were pelleted and

10 supernatants were transferred to $2.0 \mathrm{ml}$ screw-top tubes with O-rings containing magnetic

11 beads (SureBeads Protein G Magnetic Beads, NEB) coupled to antibodies (anti-pan Ago

12 antibody, clone 2A8; Sigma Millipore). $10 \%$ of supernatants were kept for input (in TRIzol). The

13 tubes were sealed, decontaminated and placed inside $15 \mathrm{ml}$ screw-top falcon tubes. The $15 \mathrm{ml}$

14 falcon tubes were decontaminated and transferred to the fridge containing the rotator where the

15 immunoprecipitation took place. After $6 \mathrm{~h}$, the beads were washed inside BSC 7 times with NET-

162 by gentle pipetting and with using a magnetic stand. Finally, the magnetic beads were

17 resuspended in $1 \mathrm{ml}$ of TRIzol. Described procedures were performed in a Biosafety Level 3

18 laboratory and were approved by the Yale University Biosafety Committee. RNA isolation and

19 library preparation (as described above) was performed under BSL2+ confinement.

For anti-HA IP, $5 \times 10^{6}$ of Calu-3 cells, transduced with either EV or Ago2, were infected

21 with SARS-CoV-2 at MOI 0.1 for $48 \mathrm{~h}$. Cells were detached with trypsin-EDTA, pelleted and

22 resuspended in $2 \mathrm{ml}$ of Pierce IP Lysis Buffer (Thermo Fisher). Cells were incubated at room

23 temperature for 30 min (approved by the Yale University Biosafety Committee SARS-CoV-2

24 inactivation method). After this time, the samples were moved to the BSL2+ laboratory,

25 sonicated using a Diagenode Bioruptor Pico sonication device, and IP was performed using 
1 Anti-HA Magnetic Beads (Pierce). Beads were resuspended in TRIzol, RNA was extracted and

2 analyzed by Northern blot as described above.

4 Western blot analysis. IPs were done as described above (excluding SARS-CoV-2 infection),

5 supernatants were mixed with 4 X SDS-PAGE loading buffer. Typically, $25 \mu \mathrm{l}$ (corresponding to

$6 \sim 40 \mu \mathrm{g}$ total protein) were separated on a 10\% SDS-PAGE gel, and electrotransferred to a

7 PVDF membrane (BioRad). After blocking with 5s\% milk in 1× TBST (20 mM Tris [pH 7.5], 150

$8 \mathrm{mM} \mathrm{NaCl}, 0.1 \%$ Tween 20 ), the membrane was probed with the appropriate antibodies and

9 detected with Western Lightning Plus-ECL (PerkinElmer) using a Gbox (SYNGENE). Primary

10 antibodies used were anti-FLAG M2 (Sigma Millipore), anti-Ago2 (MA5-23515, Invitrogen) and

11 anti-GAPDH (Cell Signaling).

13 Target predictions. Custom Perl scripts that use the RNAduplex algorithm - part of the

14 Vienna RNA Package (53) - were used to hybridize the vmiR-5p sequence to mRNA

15 transcripts obtained from GENCODE (v38) (74) fragmented into 50-nt windows with 5-bp steps.

16 Fragments with the lowest hybridization energy $(\Delta \mathrm{G})$ were chosen for further analysis.

18 Synthetic RNA transfections and qPCR. Synthetic RNAs (see Table 2 for sequences) were

19 annealed by heating equimolar concentrations for $1 \mathrm{~min}$ at $90^{\circ} \mathrm{C}$ in siRNA buffer (Horizon, 60

$20 \mathrm{mM} \mathrm{KCl}, 6 \mathrm{mM} \mathrm{HEPES}-\mathrm{pH} 7.5,0.2 \mathrm{mM} \mathrm{MgCl}$ ) and then incubating for $1 \mathrm{~h}$ at $37^{\circ} \mathrm{C} .5 \times 10^{5}$

21 HEK293T cells were transfected with $30 \mu \mathrm{M}$ of either vmiR-5p or control siRNA, by using

22 Lipofectamine RNAiMAX Transfection Reagent (Invitrogen). Cells were collected $48 \mathrm{~h}$ later,

23 RNA extractions were performed using TRIzol, samples were treated with RQ1 DNase

24 (Promega). cDNA was made using SuperScript III and random primers (Invitrogen), and qPCR 
1 was performed using FastStart Essential DNA Green Master (Roche). Primer sequences are

2 given in Table 2. Results were analyzed using the comparative Ct method (75).

$4 \quad$ In vitro RNA transcription and processing. The sequences were PCR amplified from

5 templates containing desired mutations and by using flanking primers; the forward primer

6 contained the T7 promoter (see Table 2 for sequences). The product was purified and used for

7 in vitro transcription at a final concentration $25 \mathrm{ng} / \mu \mathrm{l}$. The reaction was carried out for $4 \mathrm{~h}$ at

$837^{\circ} \mathrm{C}$ and contained $400 \mathrm{mM}$ HEPES pH 7.5, $120 \mathrm{mM} \mathrm{MgCl}$, $200 \mathrm{mM}$ DTT, $10 \mathrm{mM}$ Spermidine,

$94 \mathrm{mM}$ of each rNTPs, $20 \mathrm{U}$ RNase Inhibitor (Roche), and $5 \mathrm{U}$ of laboratory-made T7 RNA

10 polymerase. The product was purified by $8 \mathrm{M}$ urea $6 \%$ polyacrylamide gel electrophoresis

11 (PAGE), extracted in G-50 buffer (20 mM Tris pH 7.5, 0.3 M NaOAc, 2 mM EDTA, 0.1\% SDS),

12 and phenol extracted. To ensure hairpin formation, RNAs were annealed by heating in siRNA

13 buffer for $1 \mathrm{~min}$ at $90^{\circ} \mathrm{C}$ and then incubating for $1 \mathrm{~h}$ at $37^{\circ} \mathrm{C}$.

$145 \times 10^{5}$ cells (HEK293Ts, Huh7.5 or Huh7.5 KO) were transfected with $30 \mu \mathrm{M}$ of in vitro

15 transcribed RNAs, by using Lipofectamine RNAiMAX Transfection Reagent (Invitrogen). Cells

16 were collected $6 \mathrm{~h}$ later, RNA extractions were performed using TRIzol and samples were

17 processed for Northern blotting as described above.

19 Luciferase reporter assays. 4 sites complementary to vmiR-5p (or scrambled sequence as

20 control) separated by $20 \mathrm{nt}$ were PCR amplified using four primers overlapping at the unique

21 spacer sequences (listed in Table 2). The PCR products were cloned downstream of Renilla

22 luciferase of psiCHECK(TM)-2 vector (Promega) using Xhol and Notl sites.

24 transcribed RNAs, by using Lipofectamine RNAiMAX Transfection Reagent (Invitrogen). Cells

25 were collected $6 \mathrm{~h}$ later, RNA extractions were performed using TRIzol and samples were 
1 processed for Northern blotting as described above. 2 4h later, 10 ng psiCHECK reporters and

$22 \mu \mathrm{g}$ pBlueScript II (Stratagene) were transfected using TransIT-293 Transfection Reagent

3 (Mirus). After additional 24h, Firefly and Renilla luciferase activities were measured by the Dual-

4 Luciferase Reporter Assay System (Promega) on a GloMax-Multi+ Microplate Multimode

5 Reader (Promega) according to the manufacturer's instructions.

6

7

8

Pawlica et al, page 20 
1. Planas D, Veyer D, Baidaliuk A, Staropoli I, Guivel-Benhassine F, Rajah MM, Planchais C, Porrot F, Robillard N, Puech J, Prot M, Gallais F, Gantner P, Velay A, Le Guen J, KassisChikhani N, Edriss D, Belec L, Seve A, Courtellemont L, Pere H, Hocqueloux L, Fafi-Kremer S, Prazuck T, Mouquet H, Bruel T, Simon-Loriere E, Rey FA, Schwartz O. Reduced sensitivity of SARS-CoV-2 variant Delta to antibody neutralization. Nature. $2021 ; 596(7871): 276-80$. Epub 2021/07/09. doi: 10.1038/s41586-021-03777-9. PubMed PMID: 34237773.

2. Bartel DP. Metazoan MicroRNAs. Cell. 2018;173(1):20-51. doi: 10.1016/j.cell.2018.03.006. PubMed PMID: 29570994.

3. Valencia-Sanchez MA, Liu J, Hannon GJ, Parker R. Control of translation and mRNA degradation by miRNAs and siRNAs. Genes Dev. 2006;20(5):515-24. Epub 2006/03/03. doi: 10.1101/gad.1399806. PubMed PMID: 16510870.

4. Withers JB, Mondol V, Pawlica P, Rosa-Mercado NA, Tycowski KT, Ghasempur S, Torabi SF, Steitz JA. Idiosyncrasies of Viral Noncoding RNAs Provide Insights into Host Cell Biology. Annu Rev Virol. 2019. Epub 2019/05/01. doi: 10.1146/annurev-virology-092818015811. PubMed PMID: 31039329.

5. Cox JE, Sullivan CS. Balance and Stealth: The Role of Noncoding RNAs in the Regulation of Virus Gene Expression. Annu Rev Virol. 2014;1(1):89-109. Epub 2014/11/03. doi: 10.1146/annurev-virology-031413-085439. PubMed PMID: 26958716.

6. Pawlica P, Sheu-Gruttadauria J, MacRae IJ, Steitz JA. How Complementary Targets Expose the microRNA 3' End for Tailing and Trimming during Target-Directed microRNA Degradation. Cold Spring Harb Symp Quant Biol. 2020. Epub 2020/02/06. doi: 10.1101/sqb.2019.84.039321. PubMed PMID: 32019864.

7. McCaskill J, Praihirunkit P, Sharp PM, Buck AH. RNA-mediated degradation of microRNAs: A widespread viral strategy? RNA Biol. 2015;12(6):579-85. Epub 2015/04/08. doi: 10.1080/15476286.2015.1034912. PubMed PMID: 25849078; PMCID: PMC4615357.

8. Backes S, Shapiro JS, Sabin LR, Pham AM, Reyes I, Moss B, Cherry S, tenOever BR. Degradation of host microRNAs by poxvirus poly $(A)$ polymerase reveals terminal RNA methylation as a protective antiviral mechanism. Cell Host Microbe. 2012;12(2):200-10. Epub 2012/08/21. doi: 10.1016/j.chom.2012.05.019. PubMed PMID: 22901540; PMCID: PMC3782087.

9. Mishra R, Kumar A, Ingle H, Kumar H. The Interplay Between Viral-Derived miRNAs and Host Immunity During Infection. Front Immunol. 2019;10:3079. Epub 2020/02/11. doi: 10.3389/fimmu.2019.03079. PubMed PMID: 32038626; PMCID: PMC6989438.

10. Morales L, Oliveros JC, Fernandez-Delgado R, tenOever BR, Enjuanes L, Sola I. SARSCoV-Encoded Small RNAs Contribute to Infection-Associated Lung Pathology. Cell Host Microbe. 2017;21(3):344-55. Epub 2017/02/22. doi: 10.1016/j.chom.2017.01.015. PubMed PMID: 28216251; PMCID: PMC5662013.

11. Cheng Z, Cheng L, Lin J, Lunbiao C, Chunyu L, Guoxin S, Rui X, Xiangnan G, Changxing L, Yan C, Baoli Z, Wei Z. Verification of SARS-CoV-2-Encoded small RNAs and contribution to Infection-Associated lung inflammation. bioRxiv. 2021:2021.05.16.444324. doi: 10.1101/2021.05.16.444324.

12. Meng F, Siu GK, Mok BW, Sun J, Fung KSC, Lam JY, Wong NK, Gedefaw L, Luo S, Lee TMH, Yip SP, Huang CL. Viral MicroRNAs Encoded by Nucleocapsid Gene of SARS-CoV-2 Are Detected during Infection, and Targeting Metabolic Pathways in Host Cells. Cells. 2021;10(7). Epub 2021/08/08. doi: 10.3390/cells10071762. PubMed PMID: 34359932; PMCID:

48 PMC8307234. 
13. Karagkouni D, Paraskevopoulou MD, Chatzopoulos S, Vlachos IS, Tastsoglou S, Kanellos I, Papadimitriou D, Kavakiotis I, Maniou S, Skoufos G, Vergoulis T, Dalamagas T, Hatzigeorgiou AG. DIANA-TarBase v8: a decade-long collection of experimentally supported miRNA-gene interactions. Nucleic Acids Res. 2018;46(D1):D239-D45. Epub 2017/11/21. doi: 10.1093/nar/gkx1141. PubMed PMID: 29156006; PMCID: PMC5753203.

14. Blanco-Melo D, Nilsson-Payant BE, Liu WC, Uhl S, Hoagland D, Moller R, Jordan TX, Oishi K, Panis M, Sachs D, Wang TT, Schwartz RE, Lim JK, Albrecht RA, tenOever BR. Imbalanced Host Response to SARS-CoV-2 Drives Development of COVID-19. Cell. 2020;181(5):1036-45 e9. Epub 2020/05/18. doi: 10.1016/j.cell.2020.04.026. PubMed PMID: $32416070 ;$ PMCID: PMC7227586.

15. Desai N, Neyaz A, Szabolcs A, Shih AR, Chen JH, Thapar V, Nieman LT, Solovyov A, Mehta A, Lieb DJ, Kulkarni AS, Jaicks C, Xu KH, Raabe MJ, Pinto CJ, Juric D, Chebib I, Colvin RB, Kim AY, Monroe R, Warren SE, Danaher P, Reeves JW, Gong J, Rueckert EH, Greenbaum BD, Hacohen N, Lagana SM, Rivera MN, Sholl LM, Stone JR, Ting DT, Deshpande V. Temporal and spatial heterogeneity of host response to SARS-CoV-2 pulmonary infection. Nat Commun. 2020;11(1):6319. Epub 2020/12/11. doi: 10.1038/s41467-020-20139-7. PubMed PMID: 33298930; PMCID: PMC7725958.

16. Finkel Y, Gluck A, Nachshon A, Winkler R, Fisher T, Rozman B, Mizrahi O, Lubelsky Y, Zuckerman B, Slobodin B, Yahalom-Ronen Y, Tamir H, Ulitsky I, Israely T, Paran N, Schwartz M, Stern-Ginossar N. SARS-CoV-2 uses a multipronged strategy to impede host protein synthesis. Nature. 2021;594(7862):240-5. Epub 2021/05/13. doi: 10.1038/s41586-021-03610-3. PubMed PMID: 33979833.

17. Geekiyanage H, Rayatpisheh S, Wohlschlegel JA, Brown R, Jr., Ambros V. Extracellular microRNAs in human circulation are associated with miRISC complexes that are accessible to anti-AGO2 antibody and can bind target mimic oligonucleotides. Proceedings of the National Academy of Sciences of the United States of America. 2020;117(39):24213-23. Epub 2020/09/16. doi: 10.1073/pnas.2008323117. PubMed PMID: 32929008; PMCID: PMC7533700. 18. Sanz-Rubio D, Martin-Burriel I, Gil A, Cubero P, Forner M, Khalyfa A, Marin JM. Stability of Circulating Exosomal miRNAs in Healthy Subjects. Sci Rep. 2018;8(1):10306. Epub 2018/07/10. doi: 10.1038/s41598-018-28748-5. PubMed PMID: 29985466; PMCID: PMC6037782.

19. Redondo N, Zaldivar-Lopez S, Garrido JJ, Montoya M. SARS-CoV-2 Accessory Proteins in Viral Pathogenesis: Knowns and Unknowns. Front Immunol. 2021;12:708264. Epub 2021/07/27. doi: 10.3389/fimmu.2021.708264. PubMed PMID: 34305949; PMCID: PMC8293742.

20. Medley JC, Panzade G, Zinovyeva AY. microRNA strand selection: Unwinding the rules. Wiley Interdiscip Rev RNA. 2021;12(3):e1627. Epub 2020/09/22. doi: 10.1002/wrna.1627. PubMed PMID: 32954644; PMCID: PMC8047885.

21. Andrews RJ, O'Leary CA, Tompkins VS, Peterson JM, Haniff HS, Williams C, Disney MD, Moss WN. A map of the SARS-CoV-2 RNA structurome. NAR Genom Bioinform. 2021;3(2):Iqab043. Epub 2021/05/29. doi: 10.1093/nargab/lqab043. PubMed PMID: 34046592; PMCID: PMC8140738.

22. Huston NC, Wan H, Strine MS, de Cesaris Araujo Tavares R, Wilen CB, Pyle AM. Comprehensive in vivo secondary structure of the SARS-CoV-2 genome reveals novel regulatory motifs and mechanisms. Mol Cell. 2021;81(3):584-98 e5. Epub 2021/01/15. doi: 10.1016/j.molcel.2020.12.041. PubMed PMID: 33444546; PMCID: PMC7775661. 23. Sun L, Li P, Ju X, Rao J, Huang W, Ren L, Zhang S, Xiong T, Xu K, Zhou X, Gong M, Miska E, Ding Q, Wang J, Zhang QC. In vivo structural characterization of the SARS-CoV-2 RNA genome identifies host proteins vulnerable to repurposed drugs. Cell. $2021 ; 184(7): 1865-83$ e20. Epub 2021/02/27. doi: 10.1016/j.cell.2021.02.008. PubMed PMID: 33636127; PMCID:

51 PMC7871767. 
24. Manfredonia I, Nithin C, Ponce-Salvatierra A, Ghosh P, Wirecki TK, Marinus T, Ogando NS, Snijder EJ, van Hemert MJ, Bujnicki JM, Incarnato D. Genome-wide mapping of SARSCoV-2 RNA structures identifies therapeutically-relevant elements. Nucleic Acids Res. 2020;48(22):12436-52. Epub 2020/11/10. doi: 10.1093/nar/gkaa1053. PubMed PMID: 33166999; PMCID: PMC7736786.

25. Lan TCT, Allan MF, Malsick LE, Khandwala S, Nyeo SSY, Sun Y, Guo JU, Bathe M, Griffiths A, Rouskin S. Insights into the secondary structural ensembles of the full SARS-CoV-2 RNA genome in infected cells. bioRxiv. 2021:2020.06.29.178343. doi: 10.1101/2020.06.29.178343.

26. Ambros V, Bartel B, Bartel DP, Burge CB, Carrington JC, Chen X, Dreyfuss G, Eddy SR, Griffiths-Jones S, Marshall M, Matzke M, Ruvkun G, Tuschl T. A uniform system for microRNA annotation. RNA. 2003;9(3):277-9. Epub 2003/02/20. doi: 10.1261/rna.2183803. PubMed PMID: 12592000; PMCID: PMC1370393.

27. Sheu-Gruttadauria J, Pawlica P, Klum SM, Wang S, Yario TA, Schirle Oakdale NT, Steitz JA, MacRae IJ. Structural Basis for Target-Directed MicroRNA Degradation. Mol Cell. 2019;75(6):1243-55 e7. Epub 2019/07/30. doi: 10.1016/j.molcel.2019.06.019. PubMed PMID: 31353209; PMCID: PMC6754277.

28. Du Q, Thonberg $\mathrm{H}$, Wang J, Wahlestedt $\mathrm{C}$, Liang Z. A systematic analysis of the silencing effects of an active siRNA at all single-nucleotide mismatched target sites. Nucleic Acids Res. 2005;33(5):1671-7. Epub 2005/03/23. doi: 10.1093/nar/gki312. PubMed PMID: 15781493; PMCID: PMC1069010.

29. Jackson AL, Bartz SR, Schelter J, Kobayashi SV, Burchard J, Mao M, Li B, Cavet G, Linsley PS. Expression profiling reveals off-target gene regulation by RNAi. Nature Biotechnology. 2003;21(6):635-7. doi: 10.1038/nbt831.

30. Roy S, Guler R, Parihar SP, Schmeier S, Kaczkowski B, Nishimura H, Shin JW, Negishi Y, Ozturk M, Hurdayal R, Kubosaki A, Kimura Y, de Hoon MJ, Hayashizaki Y, Brombacher F, Suzuki H. Batf2/Irf1 induces inflammatory responses in classically activated macrophages, lipopolysaccharides, and mycobacterial infection. J Immunol. 2015;194(12):6035-44. Epub 2015/05/10. doi: 10.4049/jimmunol.1402521. PubMed PMID: 25957166.

31. Milewska A, Zarebski M, Nowak P, Stozek K, Potempa J, Pyrc K. Human coronavirus NL63 utilizes heparan sulfate proteoglycans for attachment to target cells. J Virol. 2014;88(22):13221-30. Epub 2014/09/05. doi: 10.1128/JVI.02078-14. PubMed PMID: 25187545; PMCID: PMC4249106.

32. Luna JM, Scheel TK, Danino T, Shaw KS, Mele A, Fak JJ, Nishiuchi E, Takacs CN, Catanese MT, de Jong YP, Jacobson IM, Rice CM, Darnell RB. Hepatitis C virus RNA functionally sequesters miR-122. Cell. 2015;160(6):1099-110. Epub 2015/03/15. doi: 10.1016/j.cell.2015.02.025. PubMed PMID: 25768906; PMCID: PMC4386883.

33. Wyler E, Mosbauer K, Franke V, Diag A, Gottula LT, Arsie R, Klironomos F, Koppstein D, Honzke K, Ayoub S, Buccitelli C, Hoffmann K, Richter A, Legnini I, Ivanov A, Mari T, Del Giudice S, Papies J, Praktiknjo S, Meyer TF, Muller MA, Niemeyer D, Hocke A, Selbach M, Akalin A, Rajewsky N, Drosten C, Landthaler M. Transcriptomic profiling of SARS-CoV-2 infected human cell lines identifies HSP90 as target for COVID-19 therapy. iScience. 2021;24(3):102151. Epub 2021/02/16. doi: 10.1016/j.isci.2021.102151. PubMed PMID: 33585804; PMCID: PMC7866843.

34. Mi B, Xiong Y, Zhang C, Zhou W, Chen L, Cao F, Chen F, Geng Z, Panayi AC, Sun Y, Wang L, Liu G. SARS-CoV-2-induced Overexpression of miR-4485 Suppresses Osteogenic Differentiation and Impairs Fracture Healing. Int J Biol Sci. 2021;17(5):1277-88. Epub 2021/04/20. doi: 10.7150/ijbs.56657. PubMed PMID: 33867845; PMCID: PMC8040480. 35. Li C, Hu X, Li L, Li JH. Differential microRNA expression in the peripheral blood from human patients with COVID-19. J Clin Lab Anal. 2020;34(10):e23590. Epub 2020/09/23. doi: 10.1002/jcla.23590. PubMed PMID: 32960473; PMCID: PMC7536972. 
36. Baran-Gale J, Kurtz CL, Erdos MR, Sison C, Young A, Fannin EE, Chines PS, Sethupathy P. Addressing Bias in Small RNA Library Preparation for Sequencing: A New Protocol Recovers MicroRNAs that Evade Capture by Current Methods. Front Genet. 2015;6:352. Epub 2016/01/07. doi: 10.3389/fgene.2015.00352. PubMed PMID: 26734062; PMCID: PMC4686641.

37. Coenen-Stass AML, Magen I, Brooks T, Ben-Dov IZ, Greensmith L, Hornstein E, Fratta $P$. Evaluation of methodologies for microRNA biomarker detection by next generation sequencing. RNA Biol. 2018;15(8):1133-45. Epub 2018/09/19. doi: 10.1080/15476286.2018.1514236. PubMed PMID: 30223713; PMCID: PMC6161688. 38. Peng X, Gralinski L, Ferris MT, Frieman MB, Thomas MJ, Proll S, Korth MJ, Tisoncik JR, Heise M, Luo S, Schroth GP, Tumpey TM, Li C, Kawaoka Y, Baric RS, Katze MG. Integrative deep sequencing of the mouse lung transcriptome reveals differential expression of diverse classes of small RNAs in response to respiratory virus infection. mBio. 2011;2(6). Epub 2011/11/17. doi: 10.1128/mBio.00198-11. PubMed PMID: 22086488; PMCID: PMC3221602. 39. Ma Y, Wang C, Xue M, Fu F, Zhang X, Li L, Yin L, Xu W, Feng L, Liu P. The Coronavirus Transmissible Gastroenteritis Virus Evades the Type I Interferon Response through IRE1alpha-Mediated Manipulation of the MicroRNA miR-30a-5p/SOCS1/3 Axis. J Virol. 2018;92(22). Epub 2018/09/07. doi: 10.1128/JVI.00728-18. PubMed PMID: 30185587; PMCID: PMC6206482.

40. Lai FW, Stephenson KB, Mahony J, Lichty BD. Human coronavirus OC43 nucleocapsid protein binds microRNA 9 and potentiates NF-kappaB activation. J Virol. 2014;88(1):54-65. Epub 2013/10/11. doi: 10.1128/JVI.02678-13. PubMed PMID: 24109243; PMCID: PMC3911702.

41. Mallick B, Ghosh Z, Chakrabarti J. MicroRNome analysis unravels the molecular basis of SARS infection in bronchoalveolar stem cells. PLoS One. 2009;4(11):e7837. Epub 2009/11/17. doi: 10.1371/journal.pone.0007837. PubMed PMID: 19915717; PMCID: PMC2773932.

42. te Velthuis AJW, Long JC, Bauer DLV, Fan RLY, Yen H-L, Sharps J, Siegers JY, Killip MJ, French H, Oliva-Martín MJ, Randall RE, de Wit E, van Riel D, Poon LLM, Fodor E. Mini viral RNAs act as innate immune agonists during influenza virus infection. Nature Microbiology. 2018;3(11):1234-42. doi: 10.1038/s41564-018-0240-5.

43. Weng KF, Hung CT, Hsieh PT, Li ML, Chen GW, Kung YA, Huang PN, Kuo RL, Chen LL, Lin JY, Wang RY, Chen SJ, Tang P, Horng JT, Huang HI, Wang JR, Ojcius DM, Brewer G, Shih SR. A cytoplasmic RNA virus generates functional viral small RNAs and regulates viral IRES activity in mammalian cells. Nucleic Acids Res. 2014;42(20):12789-805. Epub 2014/10/30. doi: 10.1093/nar/gku952. PubMed PMID: 25352551; PMCID: PMC4227785.

44. Parameswaran P, Sklan E, Wilkins C, Burgon T, Samuel MA, Lu R, Ansel KM, Heissmeyer V, Einav S, Jackson W, Doukas T, Paranjape S, Polacek C, dos Santos FB, Jalili R, Babrzadeh F, Gharizadeh B, Grimm D, Kay M, Koike S, Sarnow P, Ronaghi M, Ding SW, Harris E, Chow M, Diamond MS, Kirkegaard K, Glenn JS, Fire AZ. Six RNA viruses and fortyone hosts: viral small RNAs and modulation of small RNA repertoires in vertebrate and invertebrate systems. PLoS Pathog. 2010;6(2):e1000764. Epub 2010/02/20. doi: 10.1371/journal.ppat.1000764. PubMed PMID: 20169186; PMCID: PMC2820531.

45. Shi J, Sun J, Wang B, Wu M, Zhang J, Duan Z, Wang H, Hu N, Hu Y. Novel microRNAlike viral small regulatory RNAs arising during human hepatitis $A$ virus infection. FASEB J. 2014;28(10):4381-93. Epub 2014/07/09. doi: 10.1096/fj.14-253534. PubMed PMID: 25002121. 46. Hussain M, Asgari S. MicroRNA-like viral small RNA from Dengue virus 2 autoregulates its replication in mosquito cells. Proceedings of the National Academy of Sciences.

2014;111(7):2746-51. doi: 10.1073/pnas.1320123111.

47. Hussain M, Torres S, Schnettler E, Funk A, Grundhoff A, Pijlman GP, Khromykh AA, Asgari S. West Nile virus encodes a microRNA-like small RNA in the 3' untranslated region which up-regulates GATA4 mRNA and facilitates virus replication in mosquito cells. Nucleic 
Acids Res. 2012;40(5):2210-23. Epub 2011/11/15. doi: 10.1093/nar/gkr848. PubMed PMID: 22080551; PMCID: PMC3300009.

48. Kincaid RP, Chen Y, Cox JE, Rethwilm A, Sullivan CS. Noncanonical microRNA (miRNA) biogenesis gives rise to retroviral mimics of lymphoproliferative and immunosuppressive host miRNAs. mBio. 2014;5(2):e00074. Epub 2014/04/10. doi: 10.1128/mBio.00074-14. PubMed PMID: 24713319; PMCID: PMC3993851.

49. Kincaid RP, Burke JM, Sullivan CS. RNA virus microRNA that mimics a B-cell oncomiR. Proc Natl Acad Sci U S A. 2012;109(8):3077-82. Epub 2012/02/07. doi: 10.1073/pnas.1116107109. PubMed PMID: 22308400; PMCID: PMC3286953. 50. Perez JT, Varble A, Sachidanandam R, Zlatev I, Manoharan M, García-Sastre A, tenOever BR. Influenza A virus-generated small RNAs regulate the switch from transcription to replication. Proceedings of the National Academy of Sciences. 2010;107(25):11525-30. doi: 10.1073/pnas.1001984107.

51. Alexandersen S, Chamings A, Bhatta TR. SARS-CoV-2 genomic and subgenomic RNAs in diagnostic samples are not an indicator of active replication. Nat Commun. 2020;11(1):6059. Epub 2020/11/29. doi: 10.1038/s41467-020-19883-7. PubMed PMID: 33247099; PMCID: PMC7695715.

52. Nemudryi A, Nemudraia A, Wiegand T, Nichols J, Snyder DT, Hedges JF, Cicha C, Lee $\mathrm{H}$, Vanderwood KK, Bimczok D, Jutila MA, Wiedenheft B. SARS-CoV-2 genomic surveillance identifies naturally occurring truncation of ORF7a that limits immune suppression. Cell Rep. 2021;35(9):109197. Epub 2021/05/28. doi: 10.1016/j.celrep.2021.109197. PubMed PMID: 34043946; PMCID: PMC8118641.

53. Perez JT, Varble A, Sachidanandam R, Zlatev I, Manoharan M, Garcia-Sastre A, tenOever BR. Influenza A virus-generated small RNAs regulate the switch from transcription to replication. Proc Natl Acad Sci U S A. 2010;107(25):11525-30. Epub 2010/06/11. doi: 10.1073/pnas.1001984107. PubMed PMID: 20534471; PMCID: PMC2895093.

54. Helwak A, Tollervey D. Mapping the miRNA interactome by cross-linking ligation and sequencing of hybrids (CLASH). Nat Protoc. 2014;9(3):711-28. Epub 2014/03/01. doi: 10.1038/nprot.2014.043. PubMed PMID: 24577361; PMCID: PMC4033841.

55. Ding SW. RNA-based antiviral immunity. Nat Rev Immunol. 2010;10(9):632-44. Epub 2010/08/14. doi: 10.1038/nri2824. PubMed PMID: 20706278.

56. Bogerd HP, Karnowski HW, Cai X, Shin J, Pohlers M, Cullen BR. A mammalian herpesvirus uses noncanonical expression and processing mechanisms to generate viral MicroRNAs. Mol Cell. 2010;37(1):135-42. Epub 2010/02/05. doi: 10.1016/j.molcel.2009.12.016. PubMed PMID: 20129062; PMCID: PMC2818755.

57. Reese TA, Xia J, Johnson LS, Zhou X, Zhang W, Virgin HW. Identification of novel microRNA-like molecules generated from herpesvirus and host tRNA transcripts. J Virol. 2010;84(19):10344-53. Epub 2010/07/28. doi: 10.1128/JVI.00707-10. PubMed PMID: 20660200; PMCID: PMC2937766.

58. Cazalla D, Xie M, Steitz JA. A primate herpesvirus uses the integrator complex to generate viral microRNAs. Mol Cell. 2011;43(6):982-92. Epub 2011/09/20. doi: 10.1016/j.molcel.2011.07.025. PubMed PMID: 21925386; PMCID: PMC3176678. 59. Harwig A, Jongejan A, van Kampen AH, Berkhout B, Das AT. Tat-dependent production of an HIV-1 TAR-encoded miRNA-like small RNA. Nucleic Acids Res. 2016;44(9):4340-53. Epub 2016/03/18. doi: 10.1093/nar/gkw167. PubMed PMID: 26984525; PMCID: PMC4872094. 60. Addetia A, Lieberman NAP, Phung Q, Hsiang TY, Xie H, Roychoudhury P, Shrestha L, Loprieno MA, Huang ML, Gale M, Jr., Jerome KR, Greninger AL. SARS-CoV-2 ORF6 Disrupts Bidirectional Nucleocytoplasmic Transport through Interactions with Rae1 and Nup98. mBio. 2021;12(2). Epub 2021/04/15. doi: 10.1128/mBio.00065-21. PubMed PMID: 33849972; PMCID: PMC8092196. 
61. Banerjee AK, Blanco MR, Bruce EA, Honson DD, Chen LM, Chow A, Bhat P, Ollikainen N, Quinodoz SA, Loney C, Thai J, Miller ZD, Lin AE, Schmidt MM, Stewart DG, Goldfarb D, De Lorenzo G, Rihn SJ, Voorhees RM, Botten JW, Majumdar D, Guttman M. SARS-CoV-2 Disrupts Splicing, Translation, and Protein Trafficking to Suppress Host Defenses. Cell. 2020;183(5):1325-39 e21. Epub 2020/10/21. doi: 10.1016/j.cell.2020.10.004. PubMed PMID: 33080218; PMCID: PMC7543886.

62. Schubert K, Karousis ED, Jomaa A, Scaiola A, Echeverria B, Gurzeler LA, Leibundgut M, Thiel V, Muhlemann O, Ban N. SARS-CoV-2 Nsp1 binds the ribosomal mRNA channel to inhibit translation. Nat Struct Mol Biol. 2020;27(10):959-66. Epub 2020/09/11. doi: 10.1038/s41594-020-0511-8. PubMed PMID: 32908316.

63. Thoms M, Buschauer R, Ameismeier M, Koepke L, Denk T, Hirschenberger M, Kratzat $\mathrm{H}$, Hayn M, Mackens-Kiani T, Cheng J, Straub JH, Sturzel CM, Frohlich T, Berninghausen O, Becker T, Kirchhoff F, Sparrer KMJ, Beckmann R. Structural basis for translational shutdown and immune evasion by the Nsp1 protein of SARS-CoV-2. Science. 2020;369(6508):1249-55. Epub 2020/07/19. doi: 10.1126/science.abc8665. PubMed PMID: 32680882; PMCID: PMC7402621.

64. Martin M. Cutadapt removes adapter sequences from high-throughput sequencing reads. 2011. 2011;17(1):3. Epub 2011-08-02. doi: 10.14806/ej.17.1.200.

65. Langmead B, Salzberg SL. Fast gapped-read alignment with Bowtie 2. Nat Methods. 2012;9(4):357-9. Epub 2012/03/06. doi: 10.1038/nmeth.1923. PubMed PMID: 22388286; PMCID: PMC3322381.

66. Liao Y, Smyth GK, Shi W. featureCounts: an efficient general purpose program for assigning sequence reads to genomic features. Bioinformatics. 2014;30(7):923-30. Epub 2013/11/15. doi: 10.1093/bioinformatics/btt656. PubMed PMID: 24227677.

67. Kozomara A, Griffiths-Jones S. miRBase: integrating microRNA annotation and deepsequencing data. Nucleic Acids Res. 2011;39(Database issue):D152-7. doi: 10.1093/nar/gkq1027. PubMed PMID: 21037258; PMCID: PMC3013655.

68. Robinson MD, McCarthy DJ, Smyth GK. edgeR: a Bioconductor package for differential expression analysis of digital gene expression data. Bioinformatics. 2010;26(1):139-40. Epub 2009/11/17. doi: 10.1093/bioinformatics/btp616. PubMed PMID: 19910308; PMCID: PMC2796818.

69. Robinson JT, Thorvaldsdottir H, Winckler W, Guttman M, Lander ES, Getz G, Mesirov JP. Integrative genomics viewer. Nat Biotechnol. 2011;29(1):24-6. Epub 2011/01/12. doi: 10.1038/nbt.1754. PubMed PMID: 21221095; PMCID: PMC3346182.

70. Quinlan AR, Hall IM. BEDTools: a flexible suite of utilities for comparing genomic features. Bioinformatics. 2010;26(6):841-2. Epub 2010/01/30. doi:

10.1093/bioinformatics/btq033. PubMed PMID: 20110278; PMCID: PMC2832824.

71. Corman VM, Landt O, Kaiser M, Molenkamp R, Meijer A, Chu DK, Bleicker T, Brunink S, Schneider J, Schmidt ML, Mulders DG, Haagmans BL, van der Veer B, van den Brink S, Wijsman L, Goderski G, Romette JL, Ellis J, Zambon M, Peiris M, Goossens H, Reusken C, Koopmans MP, Drosten C. Detection of 2019 novel coronavirus (2019-nCoV) by real-time RTPCR. Euro Surveill. 2020;25(3). Epub 2020/01/30. doi: 10.2807/1560-

7917.ES.2020.25.3.2000045. PubMed PMID: 31992387; PMCID: PMC6988269.

72. Pall GS, Hamilton AJ. Improved northern blot method for enhanced detection of small RNA. Nat Protoc. 2008;3(6):1077-84. doi: 10.1038/nprot.2008.67. PubMed PMID: 18536652. 73. Huang HY, Lin YC, Li J, Huang KY, Shrestha S, Hong HC, Tang Y, Chen YG, Jin CN, Yu Y, Xu JT, Li YM, Cai XX, Zhou ZY, Chen XH, Pei YY, Hu L, Su JJ, Cui SD, Wang F, Xie YY, Ding SY, Luo MF, Chou CH, Chang NW, Chen KW, Cheng YH, Wan XH, Hsu WL, Lee TY, Wei FX, Huang HD. miRTarBase 2020: updates to the experimentally validated microRNA-target interaction database. Nucleic Acids Res. 2020;48(D1):D148-D54. Epub 2019/10/28. doi:

51 10.1093/nar/gkz896. PubMed PMID: 31647101; PMCID: PMC7145596. 
1 74. Frankish A, Diekhans M, Ferreira AM, Johnson R, Jungreis I, Loveland J, Mudge JM,

2 Sisu C, Wright J, Armstrong J, Barnes I, Berry A, Bignell A, Carbonell Sala S, Chrast J,

3 Cunningham F, Di Domenico T, Donaldson S, Fiddes IT, Garcia Giron C, Gonzalez JM, Grego

4 T, Hardy M, Hourlier T, Hunt T, Izuogu OG, Lagarde J, Martin FJ, Martinez L, Mohanan S, Muir

5 P, Navarro FCP, Parker A, Pei B, Pozo F, Ruffier M, Schmitt BM, Stapleton E, Suner MM,

6 Sycheva I, Uszczynska-Ratajczak B, Xu J, Yates A, Zerbino D, Zhang Y, Aken B, Choudhary

7 JS, Gerstein M, Guigo R, Hubbard TJP, Kellis M, Paten B, Reymond A, Tress ML, Flicek P.

8 GENCODE reference annotation for the human and mouse genomes. Nucleic Acids Res.

9 2019;47(D1):D766-D73. Epub 2018/10/26. doi: 10.1093/nar/gky955. PubMed PMID: 30357393;

10 PMCID: PMC6323946.

11 75. Schmittgen TD, Livak KJ. Analyzing real-time PCR data by the comparative C(T)

12 method. Nat Protoc. 2008;3(6):1101-8. Epub 2008/06/13. doi: 10.1038/nprot.2008.73. PubMed

13 PMID: 18546601.

14 76. Lai D, Proctor JR, Zhu JY, Meyer IM. R-CHIE: a web server and R package for

15 visualizing RNA secondary structures. Nucleic Acids Res. 2012;40(12):e95. Epub 2012/03/22.

16 doi: 10.1093/nar/gks241. PubMed PMID: 22434875; PMCID: PMC3384350. 


\section{$1 \quad$ Figures and figure legends}

2

A

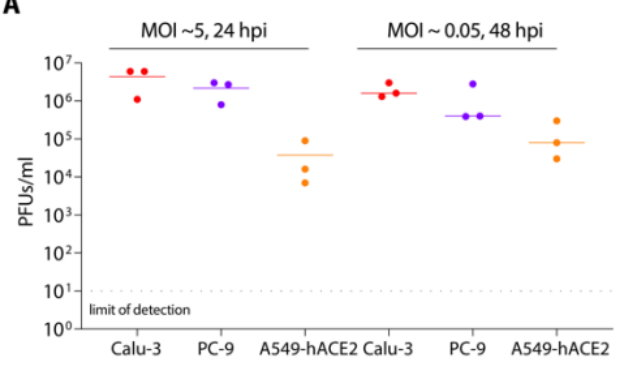

C $\quad 48 \mathrm{hpi}, \mathrm{MOI} 0.05$
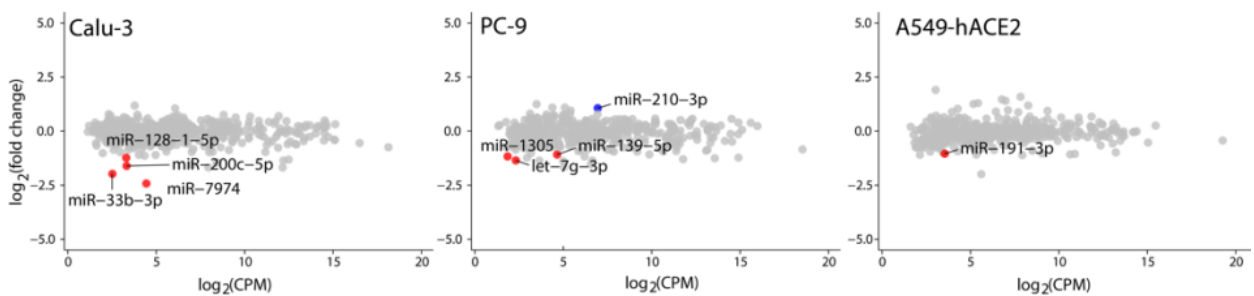

B

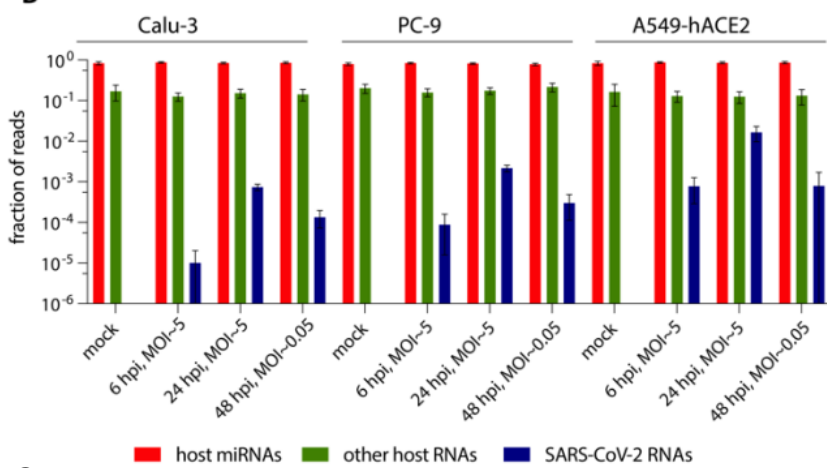

D

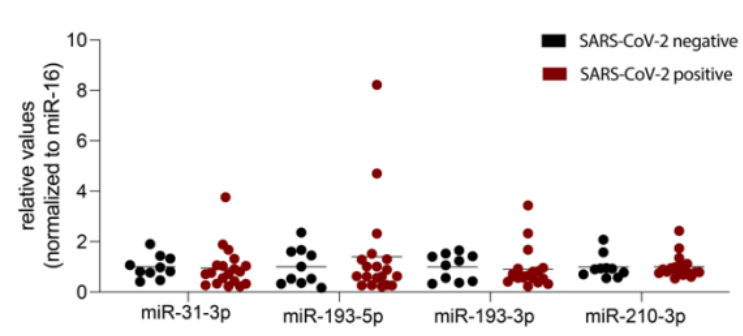

4 Figure 1. SARS-CoV-2 infection has minimal impact on host miRNA levels. A) SARS-CoV-

52 replicates in the three human lung cell lines used in this study as demonstrated by plaque

6 assays. B) Small RNA library preparation strongly enriches host miRNAs. A bar graph

7 summarizing the origin of obtained reads across the sequenced conditions. Error bars signify

8 SD. C) Plots summarizing the fold-change in host miRNA levels 48 hpi with SARS-CoV-2, $n=3$.

9 Colored dots denote miRNAs that significantly $(p<0.05)$ changed (at least two-fold).

10 Significance was calculated with edgeR. D) The relative levels of selected miRNAs are

11 unchanged in nasopharyngeal samples from SARS-CoV-2-infected patients versus uninfected

12 controls. PFUs - plaque forming units; hpi - hours post infection; MOI - multiplicity of

13 infection; CPM - counts per million. 
A

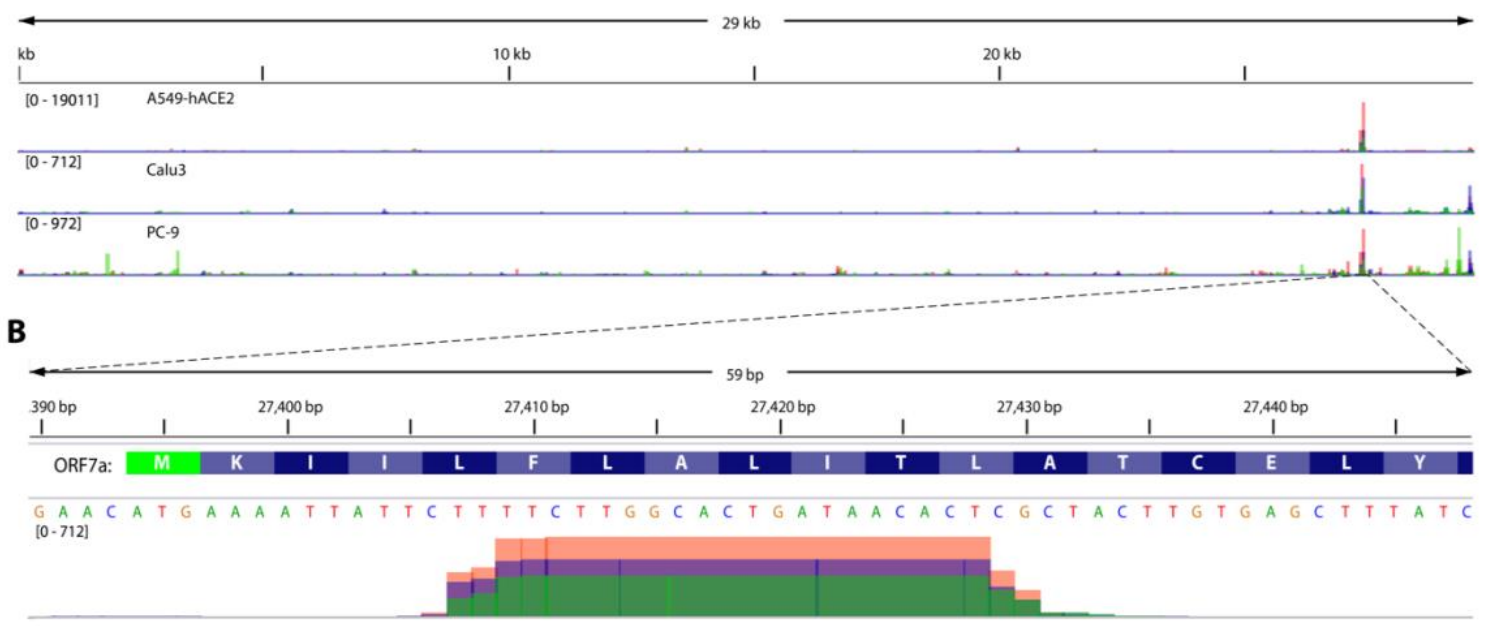

C

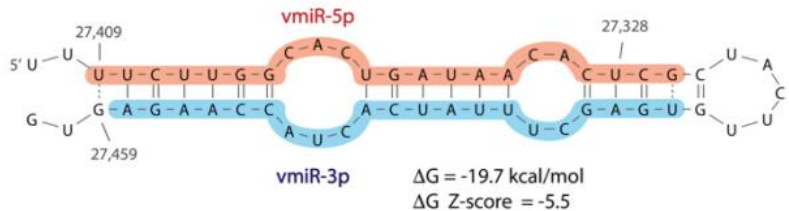

E
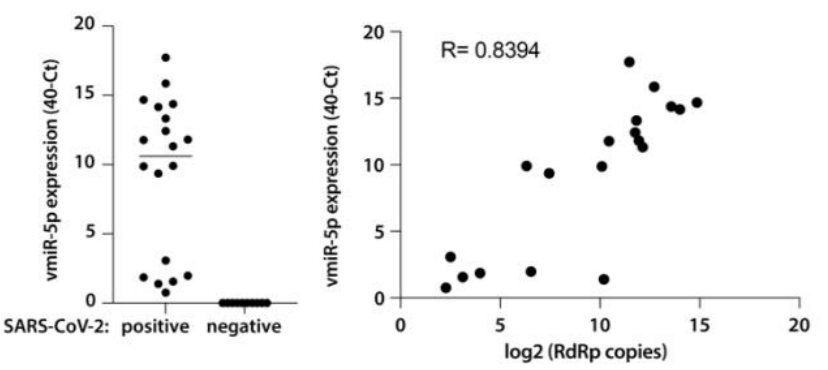

D mock $24 \mathrm{~h} 48 \mathrm{~h}$ mock $24 \mathrm{~h} 48 \mathrm{~h}$ mock $24 \mathrm{~h} 48 \mathrm{~h}$

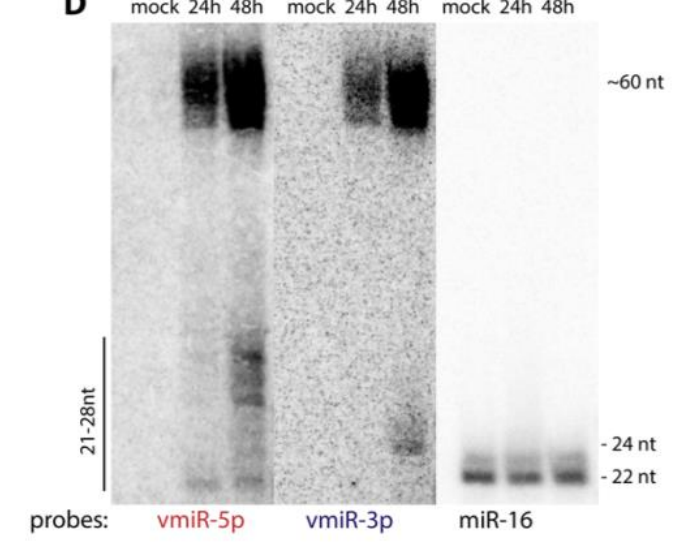

Figure 2. SARS-CoV-2 expresses a small RNA derived from the ORF7a sequence. A) Viral small RNA reads obtained from the three cell lines infected with SARS-CoV-2 map to a single distinct peak within the viral genome (data for MOI 5, 24 hpi are shown). The replicates for each cell line were overlayed on a single track (represented by different colors) and are normalized to $10^{7}$ total reads. MOI - multiplicity of infection. B) The reads coming from SARS-CoV-2 ( 20 ntlong) map near the beginning of the ORF7a gene (encoded amino acids are shown above the nucleotide sequence). Data from Calu-3 cells are shown. C) vmiR-5p forms a hairpin with the sequence immediately downstream in the viral genome. Shaded nucleotides indicate the sequences detected by Northern blot probes: pink for $5 p$ and blue for $3 p$. D) vmiR-5p can be

11 detected by Northern blotting of extracts from Calu-3 cells infected with SARS-CoV-2 at MOI 
$1 \quad 0.05$. E) As measured by custom TaqMan RT-qPCR, vmiR-5p is present in nasopharyngeal

2 samples from SARS-CoV-2-infected individuals (right panel), with its levels correlating with viral

3 load (left panel). RdRp - RNA-dependent RNA polymerase.

4

5

Pawlica et al, page 30 
A
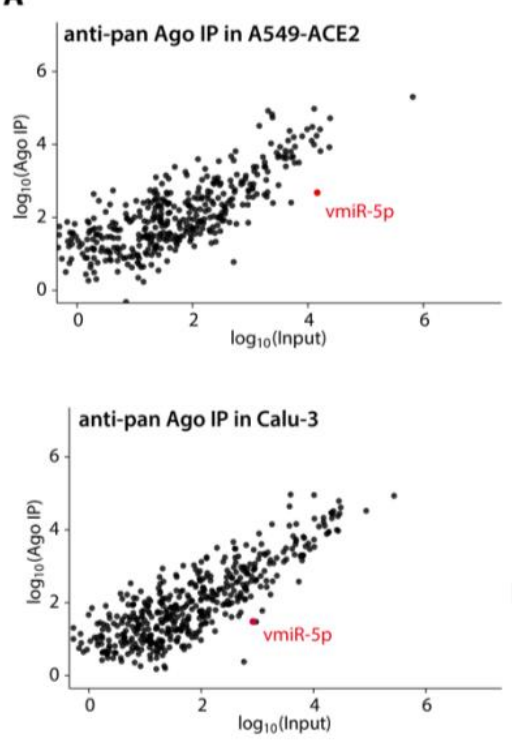

C

$$
\begin{aligned}
& \text { vmiR-5p 5. UUCUUGGCACUGAUAACACUC }
\end{aligned}
$$

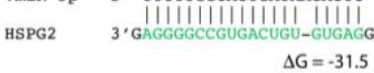

$$
\begin{aligned}
& \text { vmiR-5p 5' UUCUUGgCacugauaAcacuc } \\
& \text { Batg2 3. GaAGaAccgugacuuuUgugaug } \\
& \Delta G=-30.4
\end{aligned}
$$

\section{B}

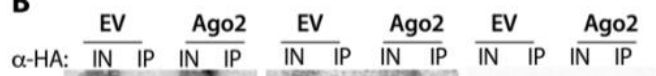
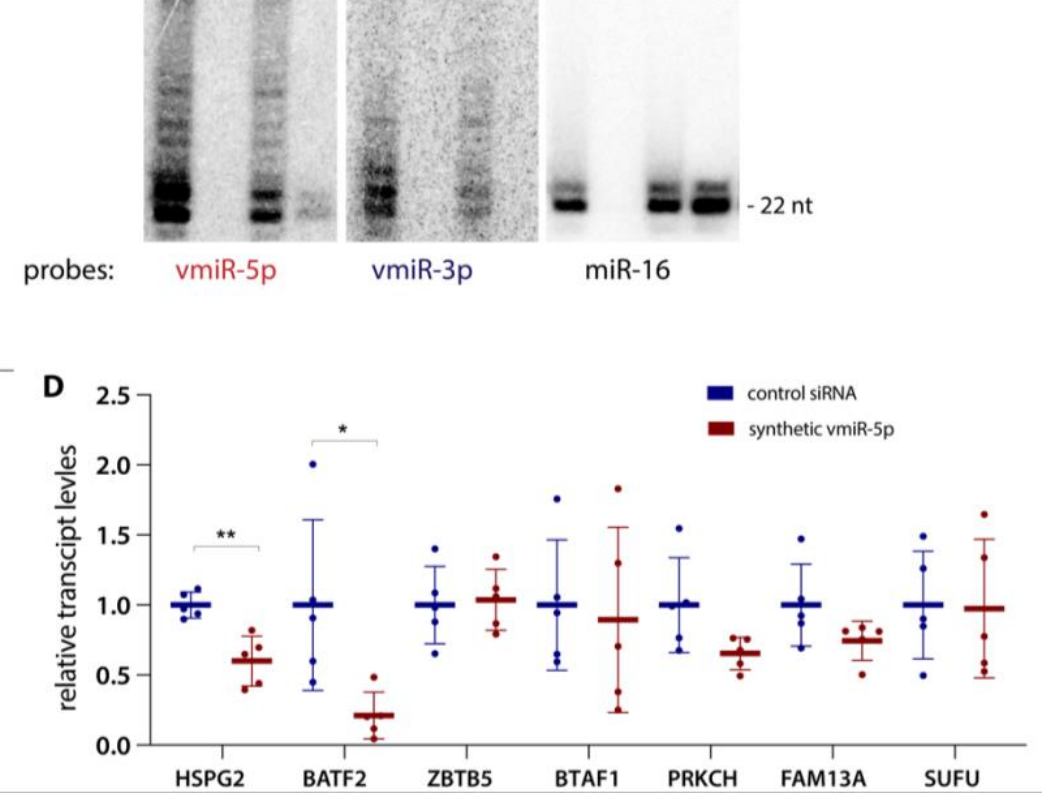

Figure 3. vmiR-5p associates with Argonaute and has the capacity to repress the levels

of host transcripts. A) vmiR-5p associates with Ago proteins and its levels are comparable to those of moderately expressed host miRNAs. Anti-pan-Ago RNA Immunoprecipitation followed by sequencing was performed on extracts of Calu-3 and A549-hACE2 cells infected with SARSCoV-2 at MOI 5 for 24h. Each plot shows the average of three independent experiments. B) vmiR-5p is selectively loaded on Ago2. Representative Northern blots for viRNA5p and viRNA3p showing anti-HA IP from Calu-3 cells transduced with either empty vector (EV) or with FLAG-HA-tagged Ago2 (Ago2). IN - input, 10\%. The miR-16 lanes provide size markers. C) Predicted interactions between vmiR-5p and sequences from the CDSs of two targeted host mRNAs. D) Synthetic vmiR-5p downregulates host gene expression. HEK293T cells were transfected with synthetic vmiR-5p (annealed to a passenger strand) and levels of seven 
1 selected host transcripts shown in Table 1 were measured by RT-qPCR $24 \mathrm{~h}$ later. Means with

2 SD are shown. * $-p<0.05$ and ${ }^{* *}-p<0.01$ as calculated by two-tailed paired t-test.

\begin{tabular}{|c|c|c|c|c|c|c|}
\hline gene & sequence & seed bp & gene & vmiR-5p & $\Delta \mathrm{G}$ & location \\
\hline HSPG2 & GGAGTGTGTCAGTGCCGGGGAG & YES & 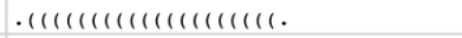 & 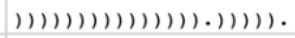 & -31.5 & $\operatorname{CDS}$ \\
\hline SUFU & TGAGTGGTGTCAGTGCCAAGT & NO & $\cdot 1111(1) 111111111111$. & 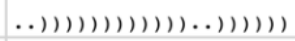 & -31.1 & $\operatorname{CDS}$ \\
\hline BATF2 & CCCTAGTAGTGIITICAGTGCCAAGAAG & YES & 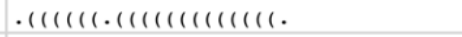 & 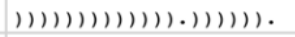 & -30.4 & $\operatorname{CDS}$ \\
\hline ZBTB5 & GGAGTTGTGGTCAGTGCCGAGAAG & YES & $\cdot 1(1 \cdot 11(\cdot) 111(1)(1)(1)(1)$ & 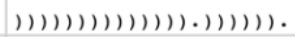 & -29.9 & CDS \\
\hline SLC30A3 & CGGGATACGCTGTTGTCGGTGCCAGGAGT & YES & 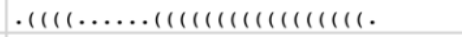 & 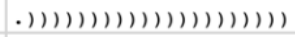 & -28.9 & $\operatorname{cDS}$ \\
\hline LAMA3 & GGAGTGTGCCAGTGCCGAGAG & YES & 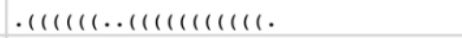 & $().(1)())(1))(.).(1))$. & -28.7 & CDS \\
\hline MCF2L2 & GGGGTGTTCGTGTTAGTGCCAAGAT & YES & 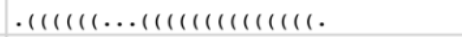 & 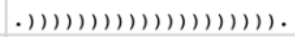 & -28.5 & 3'UTR \\
\hline BTAF1 & TGAGTGGAATCCAGTGCCGAGAAC & YES & 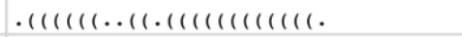 & 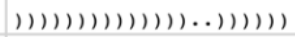 & -28.4 & CDS \\
\hline BUD23 & TGGTGGGATCAGTGCCAGGCA & NO & 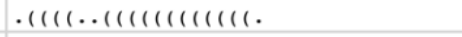 & 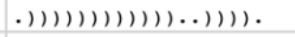 & -28.3 & 3'UTR \\
\hline FAM120C & CCGAGTGGGGCCGTCGGTGCCAGGCC & NO & 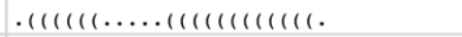 & 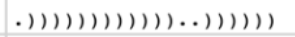 & -28.3 & CDS \\
\hline PRKCH & GGAGTGTTGGGAAACAGGGTIATCAGTGCCAAGT & NO & $\cdot 1(1(1(\ldots) \cdots \cdots \cdots) \cdots \cdots)$ & 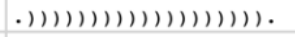 & -28.3 & $\operatorname{cDS}$ \\
\hline FAM13A & AGGGTGCTATTAGTGCCAAGTT & NO & $\cdot \cdot 11111 \cdot 111111(1111118$ & 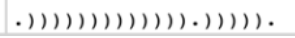 & -28 & CDS \\
\hline
\end{tabular}

6 Table 1. Identification of human transcripts highly complementary to vmiR-5p. bp — base

7 pairing. 


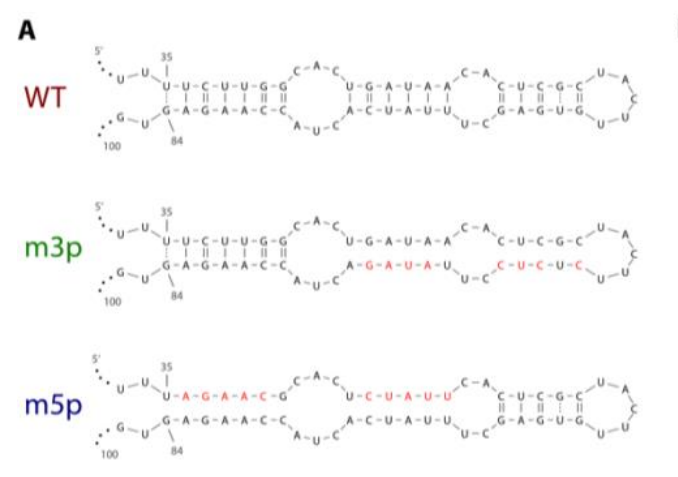

B
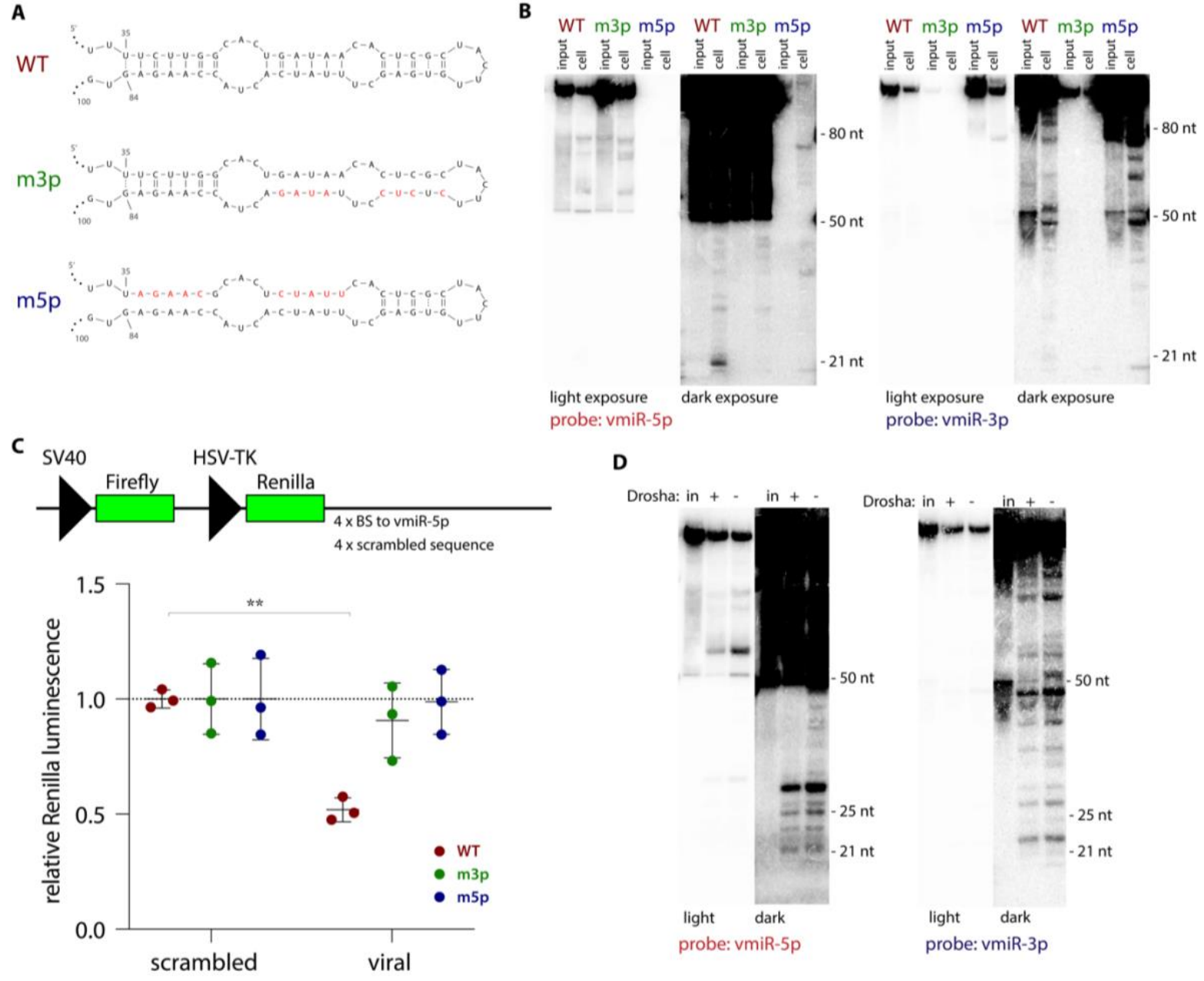

Figure 4. Production of functional vmiR-5p is Drosha-independent. A) In vitro transcripts used in this study. Red nts represent introduced mutations. B) vmiR-5p processing inside cells

4 is enhanced by the formation of a hairpin involving the downstream sequence. A representative

5 Northern blot of RNAs isolated from HEK293T cell $6 \mathrm{~h}$ post transfection with each of the in vitro

6 transcribed 100 nt-long RNA sequences shown in panel A. Input, 10\%. C) vmiR-5p processed

7 inside HEK293 cells is capable of repressing a reporter. Top panel: schematic of the

8 psiCHECK-based luciferase reporters used. Each of the four binding sites (BS) was $21 \mathrm{nt}$-long,

9 separated by unique 20 nt-long spacers. Bottom panel: vmiR-5p generated from an in vitro-

10 transcribed hairpin can regulate a luciferase reporter gene containing downstream

11 complementary sites in HEK293T cells. Means with SD are shown. ${ }^{* *}-p<0.01$ as calculated 
1 by two-tailed paired t-test. D) vmiR-5p processing is Drosha independent. A representative

2 Northern blot of RNAs isolated from either Huh7.5 or Huh7.5 Drosha knockout cells (32) $6 \mathrm{~h}$

3 post transfection with in vitro-transcribed 100 nt-long viral RNA sequence. in — input, 10\%.

4 


\section{Supplementary figures}

2

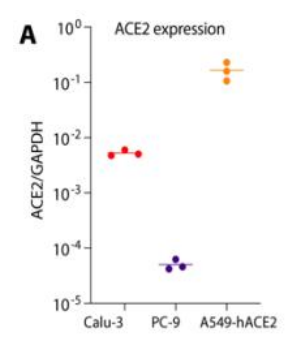

C
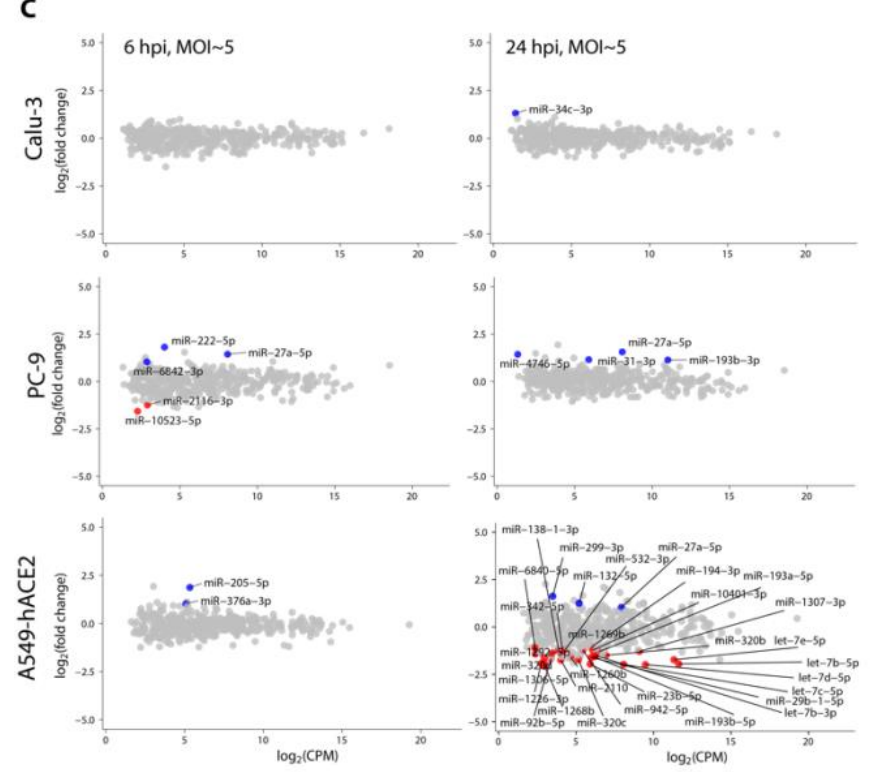

G

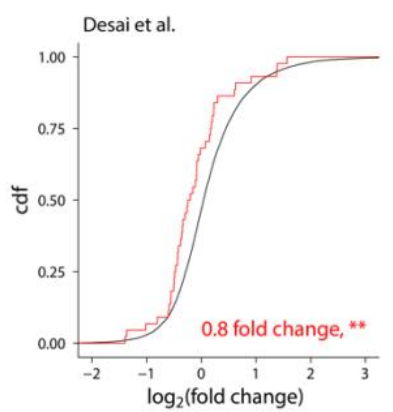

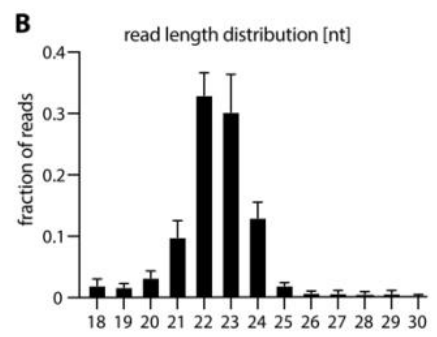

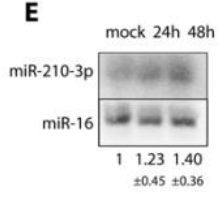

Calu-3

PC-9

A549-hACE2

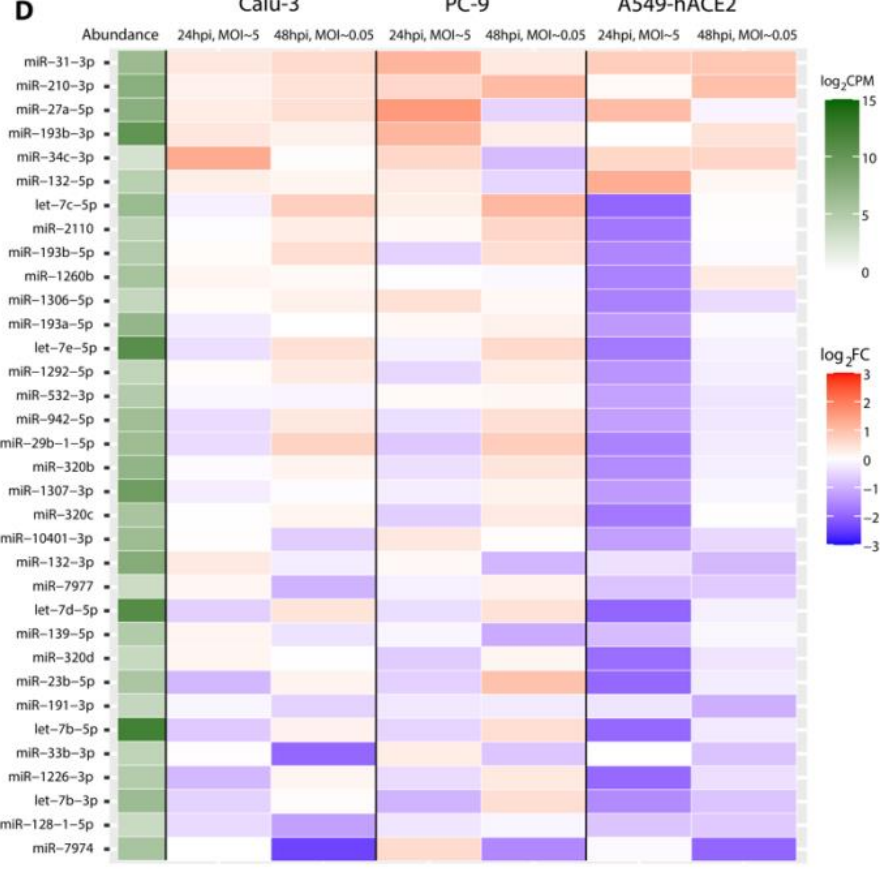

F GO term analysis of miR-210-3p targets cellular response to decreased oxygen levels cellular response to hypoxia negative regulation of cell proliferation. positive regulation of cellular catabolic process cellular response to oxidative stress negative regulation of cellular process negative regulation of histone modification transmembrane receptor protein tyrosine kinase signaling pathway second-messenger-mediated signaling embryonic cranial skeleton morphogenesis cellular protein modification process

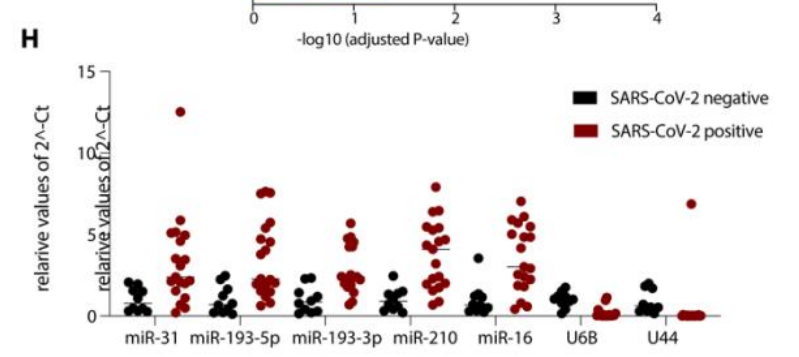

4 Figure S1. SARS-CoV-2 infection has minimal impact on host miRNA levels. A) Relative

5 transcript levels of hACE2 in the three lung cell lines used in the study. B) A bar graph

6 summarizing the sizes of obtained reads from all conditions sequenced. Error bars signify SD.

7 C) Plots summarizing the fold-change in miRNA levels upon SARS-CoV-2 infection of various

8 cell lines, $n=3$. Colored dots denote miRNAs that significantly $(p<0.05)$ changed (at least two- 
1 fold). Significance was calculated using edgeR. D) A heat-map showing fold changes (FC) in

2 miRNA levels after SARS-CoV-2 infection. The data are shown only for miRNAs that

3 significantly changed (at least 2-fold) in any of the conditions. E) Northern blot showing that

4 miR-210-3p slightly increases after infection with SARS-CoV-2 infection of Calu-3 cells at MOI

$50.05, n=5$. F) GO term analyses for miR-210-3p targets suggest that this miRNA regulates

6 responses to various stimuli. ${ }^{* *}-p=0.004$, as calculated by Wilcoxon test. G) miR-210-3p

7 targets (13) exhibit stronger downregulation than other host mRNAs after SARS-CoV-2 infection

8 in human lungs (data replotted from $(14,15)$ ). H) Host miRNAs may escape host shutoff

9 induced by SARS-CoV-2 infection. hpi — hours post infection; MOI - multiplicity of infection;

10 CPM - counts per million; cdf - cumulative distribution function. 


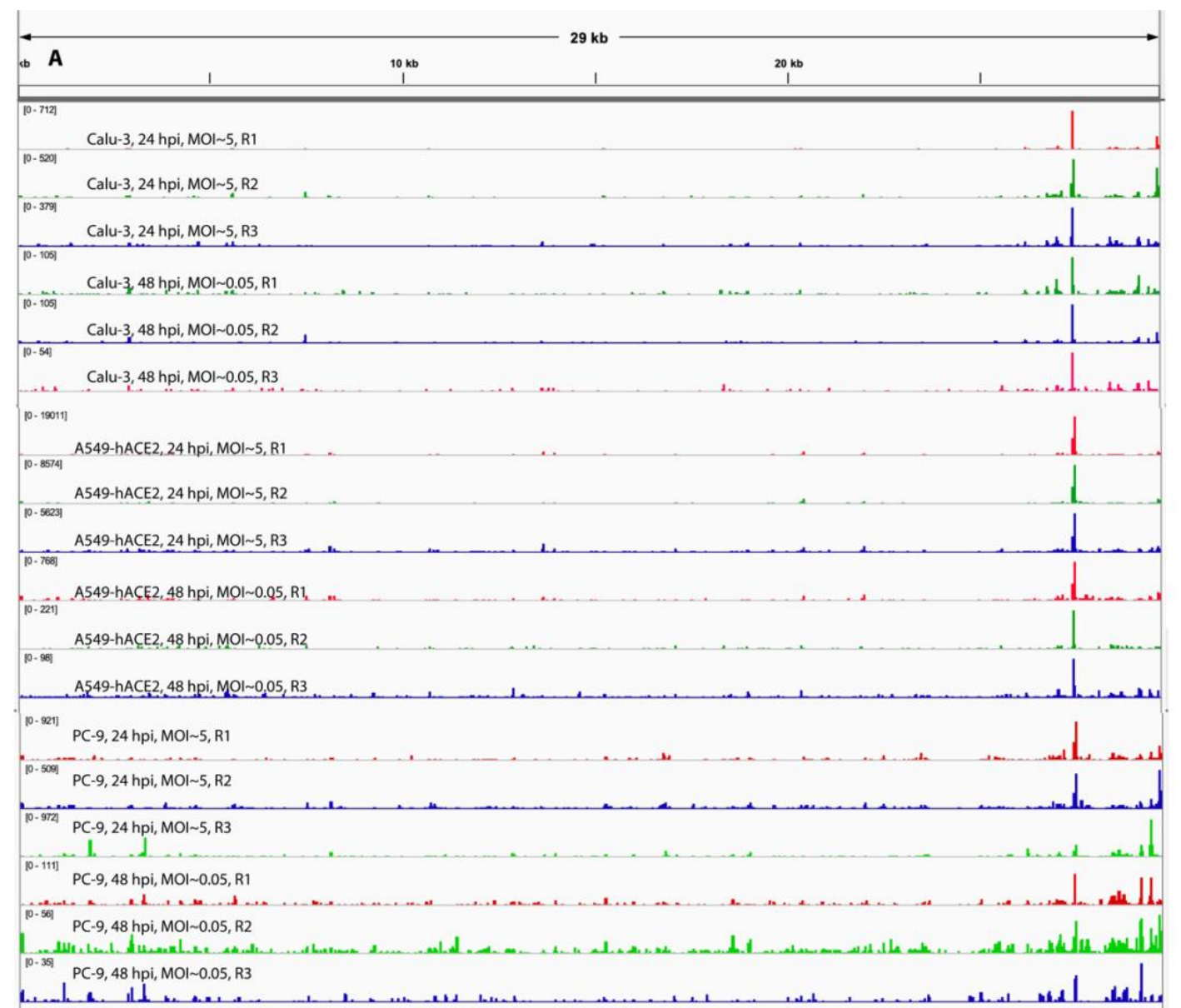

B

SARS-CoV-2 Bat coronavirus (RaTG13) Pangolin coronavirus SARS-CoV

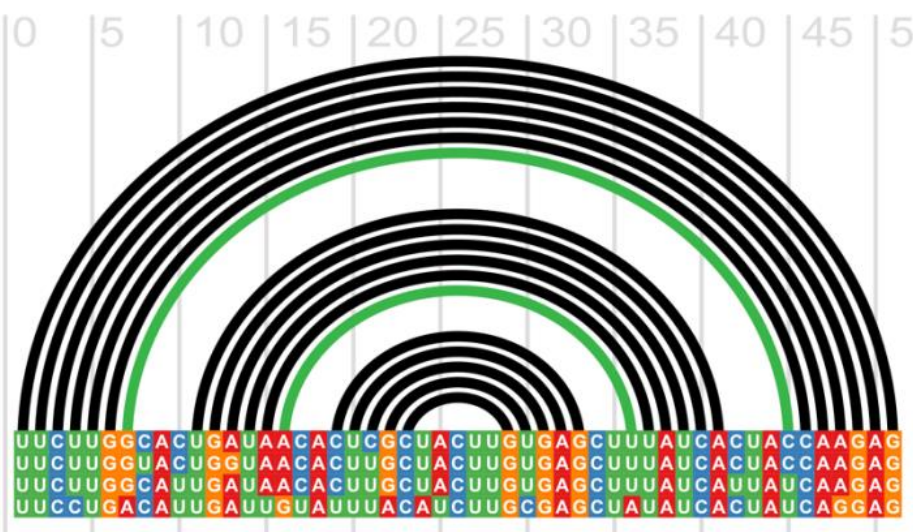

Figure S2. SARS-CoV-2 expresses a small RNA derived from the ORF7a sequence. A)

Sequencing tracks for all replicates are shown. B) Location of vmiR-5p and viRNA-3p annotated on an alignment of coronavirus reference sequences. The hairpin base pairs are indicated by arcs above the sequence alignment with the two previously identified covarying base pairs (21) indicated in green. Alignment and base pairs visualized using the program R-CHI (76). 


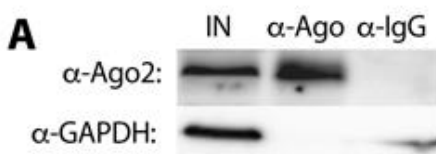

Calu-3

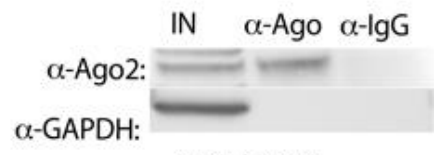

A549-hACE2

B Calu-3: $\frac{\mathrm{Ago}}{\operatorname{IN} \alpha-\mathrm{HA}} \frac{\mathrm{EV}}{\mathrm{IN} \alpha-\mathrm{HA}}$

$\alpha$-FLAG:

$\alpha$-GAPDH:

Figure S3. Western blots confirming anti-Argonaute immunoprecipitation. A) anti-pan Ago anti-FLAG antibodies.

6

\begin{tabular}{|c|c|}
\hline miR-16 probe & CGCCAATATTTACGTGCTGCTA \\
\hline miR-210-3p probe & TCAGCCGCTGTCACACGCACAG \\
\hline vmiR-5p probe & CGAGTGTTATCAGTGCCAAGAA \\
\hline viRNA-3p probe & TCTTGGTAGTGATAAAGCTCAC \\
\hline $\begin{array}{l}\text { RdRp_SARSr-F } \\
\text { (qPCR primer) }\end{array}$ & GTGARATGGTCATGTGTGGCGG \\
\hline $\begin{array}{l}\text { RdRp_SARSr-R } \\
\text { (qPCR primer) }\end{array}$ & CARATGTTAAASACACTATTAGCATA \\
\hline $\begin{array}{l}\text { RdRp_SARSr-P2 } \\
\text { (qPCR probe) }\end{array}$ & FAM-CAGGTGGAACCTCATCAGGAGATGC-BBQ \\
\hline Synthetic vmiR-5p & /5Phos/rUrUrCrUrUrGrGrCrArCrUrGrArUrArArCrArCrUrC \\
\hline $\begin{array}{l}\text { Passenger strand } \\
\text { for vmiR-5p }\end{array}$ & /5Phos/rGrUrGrUrUrArUrCrArCrUrGrCrCrUrArGrArUrUrG \\
\hline siContol & rArArGrCrGrArUrArCrCrUrCrGrUrGrUrGrUrGrArUrU \\
\hline T7_F (amplification) & GAATTTAATACGACTCACTATAGGTTCTCCTCTAAACGAACATGAA \\
\hline T7 R (amplification) & GAATGTACCTCTAACACACTCTTGGT \\
\hline WT (template) & $\begin{array}{l}\text { GGTTCTCCTCTAAACGAACATGAAAATTATTCTTTTCTTGGCACTGATAA } \\
\text { CACTCGCTACTTGTGAGCTTTATCACTACCAAGAGTGTGTTAGAGGTACA }\end{array}$ \\
\hline m3p (template) & $\begin{array}{l}\text { GGTTCTCCTCTAAACGAACATGAAAATTATTCTTTTCTTGGCACTGATAA } \\
\text { CACTCGCTACTTCTCTCCTTATAGACTACCAAGAGTGTGTTAGAGGTACA }\end{array}$ \\
\hline m5p (template) & $\begin{array}{l}\text { GGTTCTCCTCTAAACGAACATGAAAATTATTCTTTAGAACGCACTCTATT } \\
\text { CACTCGCTACTTGTGAGCTTTATCACTACCAAGAGTGTGTTAGAGGTACA }\end{array}$ \\
\hline
\end{tabular}

Table 2. Oligonucleotides used in the study 